Article

\title{
Tn6603, a Carrier of Tn5053 Family Transposons, Occurs in the Chromosome and in a Genomic Island of Pseudomonas aeruginosa Clinical Strains
}

\author{
Vaheesan Rajabal (D, Vilma A. Stanisich and Steve Petrovski *(1) \\ Department of Physiology, Anatomy and Microbiology, La Trobe University, Bundoora, VIC 3086, Australia; \\ vaheesan.r@gmail.com (V.R.); vstanisich@bigpond.com (V.A.S.) \\ * Correspondence: steve.petrovski@latrobe.edu.au; Tel.: +61-3-9479-2397
}

Received: 12 November 2020; Accepted: 8 December 2020; Published: 15 December 2020

check for updates

\begin{abstract}
Transposons of the Pseudomonas aeruginosa accessory gene pool contribute to phenotype and to genome plasticity. We studied local P. aeruginosa strains to ascertain the encroachment of mer-type res site hunter transposons into clinical settings and their associations with other functional modules. Five different Tn5053 family transposons were detected, all chromosomal. Some were solitary elements; one was in res of Tn1013\#, a relative of a reported carrier of int-type res site hunters (class 1 integrons), but most were in res of Tn6603, a new Tn501-related transposon of unknown phenotype. Most of the Tn6603::Tn elements, and some Tn6603 and Tn6603::Tn elements found in GenBank sequences, were at identical sites in an hypothetical gene of P. aeruginosa genomic island PAGI-5v. The island in clonally differing strains was at either of two tRNA ${ }^{\text {Lys }}$ loci, suggesting lateral transfer to these sites. This observation is consistent with the membership of the prototype PAGI-5 island to the ICE family of mobile genetic elements. Additionally, the res site hunters in the nested transposons occupied different positions in the Tn6603 carrier. This suggested independent insertion events on five occasions at least. Tn5053 family members that were mer-/tni-defective were found in Tn6603- and Tn501-like carriers in GenBank sequences of non-clinical Pseudomonas spp. The transposition events in these cases presumably utilized tni functions in trans, as can occur with class 1 integrons. We suggest that in the clinical context, P. aeruginosa strains that carry Tn6603 alone or in PAGI-5v can serve to disseminate functional res site hunters; these in turn can provide the requisite trans-acting tni functions to assist in the dissemination of class 1 integrons, and hence of their associated antibiotic resistance determinants.
\end{abstract}

Keywords: Tn5053 family transposons; Tn6603; clinical Pseudomonas aeruginosa; genomic island PAGI-5v; class 1 integrons; nested transposons; defective transposons; ICE family

\section{Introduction}

Pseudomonas aeruginosa is a metabolically versatile bacterium that inhabits many diverse ecological niches and is also a significant opportunistic nosocomial pathogen in humans [1,2]. The treatment of infections may be severely compromised by the organism's broad intrinsic resistance to antimicrobial agents and its ability to acquire resistance through horizontal gene transfer processes [1]. The inherited genes are frequently located within mobile genetic elements (MGEs), combinations of which contribute to the accessory gene pool of individual strains and aid in niche adaptation [3].

The rich repertoire of MGEs in P. aeruginosa includes plasmids, transposons (Tn), genomic islands (GIs), integrative and conjugative elements (ICEs), and integrons (In), which are often present in strains that exhibit combined resistance to mercury(II) (mer) and to antibiotics. The former phenotype is associated with mer transposons [4,5] or independent mer modules, for example in ICEs and GIs [6-8], 
or in combination with antibiotic-resistance genes, such as occurs in the prevalent IncP-2 plasmids and the ubiquitous IncP-1 plasmids that occur widely in Gram-negative bacteria [9-12]. Some IncP-1 plasmids have antibiotic-resistant genes that are fixed in a conserved plasmid backbone, which is often interrupted by accessory MGEs [11]. Tn21/Tn501-like elements predominate in the trfA-oriV region and include relatively simple structures (e.g., Tn1696, a mer transposon carrying In4; [13]) and complex arrangements (e.g., Tn511, with components from five MGEs; [14]). On the other

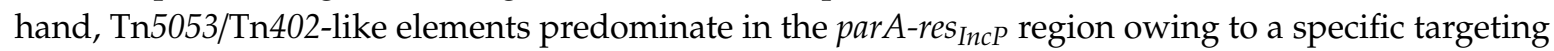
mechanism, as described below. The focus of the present study is the Tn5053 family of mer-type transposons. This group has the capacity to aid in the spread of class 1 integrons [15,16], which are prominent members of the Tn402 family and encode a multiplicity of antibiotic-resistant gene cassettes $[17,18]$.

Tn5053 and Tn402, the prototype transposons of the res site hunter family [19], probably share a common ancestor; their transposition genes are related (tniABQ-res-tniR; 83\% identity) and the elements are bordered by characteristic 25 bp inverted repeat termini (IRo and IRt) [20-22]. Less than 10 distinctive Tn5053 family members are known, based on the gene organization and sequence diversity of complete elements, although there is evidence for others ([22-24]; Figure 1). All have an exogenously captured mer module and most are functional transposons. They have been isolated from bacterial species in diverse environments, including ancient sediments, with Tn5053 being especially widespread [23,25,26]. There are few examples from the clinical setting [22,27]. Tn402 and some close relatives are also functional transposons. Their tni module has a captured int module (i.e., integrase gene, intI1, and an attI1 recombination site; [16]) located close to the site of the mer module found in the Tn5053 family. Functional Tn402-type elements (self-mobile integrons) do not appear to be common in the clinical setting $[7,28]$. Instead, many members of the Tn402 family are defective transposons (class 1 integrons) derived from a Tn402 ancestral element that lost tni genes during evolution [21,29-31]. A third Tn5053/Tn402-related family is defined by Tn6048, a multi-metal response transposon from Cupriavidus and Variovorax [32,33].

Information on the transposition process comes from studies on Tn5053, Tn502, and Tn402 [19,34-37]. These move by replicative transposition, preferentially inserting at a res site (hence the "res-site hunter" epithet) by using the associated target site resolvase and the trans-acting TniABQ proteins to form a cointegrate. This is resolved by cis-acting components (res-TniR) aided by the target site resolvase. The Tn is inserted in a preferred orientation (IRo nearest the target site resolvase gene) and is flanked by 5 bp direct repeats (DR). Not all res sites serve as suitable targets, and transposition to non-res sites is inefficient [19,37]. Class 1 integrons at their locations in res sites of various MGEs also exhibit key indicators of Tn5053/Tn402-type transposition, fostering recognition that they are defective transposons [21,29]. Indeed, such linkage to MGEs has promoted the spread of class 1 integrons among Gram-negative bacteria, including instances of Tn-In elements in ICEs and GIs $[15,17,38]$.

Mechanisms that mediate the lateral movement of class 1 integrons, independent of an MGE, remain a moot point. Theoretical considerations suggest that integrons that retain intact IRs can be mobilized if a complete tni module is provided in trans [21,29]. Experimental evidence of such events is the movement of In 0 and In2-these have retained only tniA, yet they transpose to a plasmid site

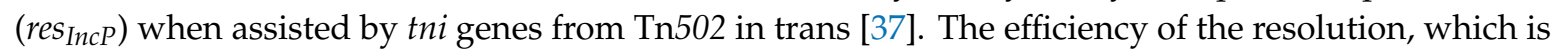
effected by the host $\operatorname{rec} A$ system and the target-site resolvase, is normal, corresponding to that seen with a fully functional element (e.g., Tn502). The movement of Tn2521 (=In33) to res IncP $_{\text {has also been }}$ observed and is suspected to have involved tni-assisted transposition by another Tn [39,40]. Similar assisted transposition events explain the occurrence of class 1 integrons in res sites of different plasmids and transposons, including mer and non-mer transposons (see [41] for references). Experimentally, Tn5053 targets some of the same res sites in transposons, as well as additional sites [19].

This study focusses on the Tn5053 family, which is one of three transposon groups that have contributed to the worldwide dissemination of mer genes in environmental bacteria [25]. Additionally, 
members of the Tn21 family are broadly distributed in clinical settings [5,26], but whether this is the case for the Tn5053 family is largely unexplored [22,27]. This aspect of the biology of the Tn5053 family warrants study, especially as class 1 integrons have on independent occasions inserted into various mer transposons, possibly in the clinical environment [27,41]. These linkage events, as described above, require the in trans supply of functional tni genes; the Tn5053 family is a possible source. We did indeed detect members of this family among locally isolated clinical strains of P. aeruginosa. Unexpectedly, most were embedded in a new carrier transposon, Tn6603, which is also often linked to the same GI. Tn6603, regardless of whether or not it is a part of the GI, has the capacity to attract res site hunters, including class 1 integrons, and to associate with MGEs. As such, Tn6603 can contribute to the ongoing adaption of $P$. aeruginosa to antimicrobials in the clinical setting, and also to the catabolic activities of Pseudomonas spp. in non-clinical environments.

\section{Materials and Methods}

\subsection{Bacterial Strains, Plasmids and Growth Media}

The Escherichia coli K-12 derivatives used were DH5 $\alpha\left(\operatorname{rec} A 1 \mathrm{Res}^{-} \mathrm{Mod}^{+} \mathrm{Nal}^{\mathrm{r}}\right)$ [42] and LT101 (recA13 Res $^{-}$Mod $^{-}$Str $^{r}$ Rifr $^{r}$ auxotroph) [43]. The Pseudomonas aeruginosa strains were PAO9503 (Str ${ }^{\mathrm{r}}$ auxotroph) [44] and 191 wild type strains from clinical sources. The properties of the plasmids used are listed in Table 1, and detailed characteristics of 12 of the clinical strains are shown in Table 2. Nutrient agar (NA) and nutrient broth (NB) have been described in [43]. For selection of E. coli strains (or $P$. aeruginosa, as indicated), antimicrobials were added to NA at the following final concentrations ( $\mu \mathrm{g}$ $\left.\times \mathrm{mL}^{-1}\right)$ : carbenicillin $(\mathrm{Cb})$ at 100 or 250 (for P. aeruginosa); chloramphenicol $(\mathrm{Cm})$ at 10 ; mercuric chloride (Hg) at 15 (for both E. coli and P. aeruginosa); nalidixic acid (Nal) at 8; streptomycin (Sm) at 100 (for both E. coli and P. aeruginosa); tetracycline hydrochloride (Tc) at 10 or 80 (for P. aeruginosa). Carbenicillin was used to select strains carrying ampicillin (Ap)-resistant plasmids. Media containing these various agents are presented in an abbreviated form. For example NA.Sm.Hg indicates nutrient agar with added streptomycin and mercuric chloride.

\subsection{Transposons and Plasmid Constructions}

The transposons and nested transposons named in Table 2 were sequenced, as was the new transposon Tn6603 isolated from P. aeruginosa PA65. The naming of new transposons in this work (i.e., Tn6603, Tn6604, Tn6606, and Tn6607) follows the recommendations of the transposon registry (https://transposon.lstmed.ac.uk) and is based on evidence of transpositional insertion and complete nucleotide sequence. The plasmids used are listed in Table 1, except for additional derivatives of pUB307 and pUB1601, which are listed in Table 2. Details of plasmid constructions involving DNA techniques are given in the footnotes to Table 1.

\subsection{Conjugation, Transposition Assays, and Analysis of Transconjugants}

Late-exponential-phase cultures in NB were used for conjugation experiments conducted using the quantitative filter method [43]. Experiments using independent cultures were performed three times and the average transfer frequency (transconjugants per donor) was calculated.

Detection of res site hunter transposons: P. aeruginosa strains were grown at $43{ }^{\circ} \mathrm{C}$ to induce a restriction-deficient phenotype [45] prior to conjugation with DH5 $\alpha$-donors carrying either pUB307 or pUB1601. Transconjugants were recovered on NA.Hg.Tc. Representative transconjugants were subjected to three cycles of subculture and subsequently used as donors in conjugations with PAO9503 grown at $43^{\circ} \mathrm{C}$. Transconjugants were recovered on NA.Sm.Hg. Plasmid DNA extracted from purified transconjugants was sequenced to determine the presence of pUB307 or pUB1601 derivatives carrying either res site hunter or nested transposons.

Characterization of Tn6603c: (a) Transposition was studied using a DH5 $\alpha$ derivative carrying pSK::Tn6603c and conjugally introduced pUB307 (or pUB1601) (selection was on NA.Nal.Tc). A mixture 
of the transconjugants was subcultured three times on NA.Nal.Tc.Cm and a donor culture prepared in $10 \mathrm{~mL}$ NB for use in an outcross to LT101. The number of transconjugants isolated on NA.Rif.Cm enabled determination of the transposition frequency. Plasmid DNA extracted from transconjugants from separate experiments was sequenced to determine the location of the inserted Tn6603c. (b) Conductional transfer was studied using a DH5 $\alpha$ derivative carrying pBR322 and conjugally introduced pSP116 (or pSP145) (selection was on NA.Km). As in (a), transconjugants were subcultured on NA.Km.Cb for subsequent use in an outcross to LT101. The number of transconjugants isolated on NA.Rif.Cb enabled determination of Tn6603c-mediated conductional transfer relative to that by Tn501. (c) Targeting of Tn502 to res $6603 c$ and res $_{\text {IncP }}$ was studied using a DH5 $\alpha$ derivative carrying pSP114 (or pVS76) and conjugally introduced pSP144 (selection was on NA.Km). As in (a), transconjugants were subcultured on NA.Km.Tc for subsequent use in an outcross to LT101. Transconjugants were isolated on NA.Rif.Tc. Plasmid DNA extracted from transconjugants from separate experiments was transformed into DH5 $\alpha$, with selection on NA.Tc. and subsequent screening to identify $\mathrm{Hg}^{\mathrm{r}} \mathrm{Km}^{\mathrm{s}}$ transformants. The resolved pSP114::Tn502 (or pVS76::Tn502) plasmids in these transformants were isolated and sequenced to determine the location of the inserted $\operatorname{Tn} 502$.

\subsection{DNA Techniques, Nextgen Sequencing, and Analysis}

Cloning, DNA manipulations, and Southern (colony lift) hybridizations were performed as described previously [46]. PCR amplification involved the use of iProof ${ }^{\mathrm{TM}}$ high fidelity DNA polymerase (Bio-Rad, Gladesville, New South Wales, Australia). Reaction mixtures were placed in a thermal cycler for 35 cycles under the following conditions: $98{ }^{\circ} \mathrm{C}, 2 \mathrm{~min}$ (first cycle only); $98^{\circ} \mathrm{C}, 30 \mathrm{~s} ; 72{ }^{\circ} \mathrm{C}, 15 \mathrm{~s} / \mathrm{kb} ; 72{ }^{\circ} \mathrm{C}, 10 \mathrm{~min}$ (last cycle only). The reaction products were detected using agarose gel electrophoresis and staining with Invitrogen SYBR safe (Thermo Fisher Scientific, Scoresby, Victoria, Australia). The digoxigenin-labelled tni $A_{502}$ probe used in hybridization was prepared from the PCR products obtained using primers VR1 (5'-GTGCGAGTGATGACGGTTG) and VR2 (5'-GTGCAGATTGATCACACGG), with pVS983 DNA as the template. Primers VR49 (5'-CCCTTCGTGCGGATAGTCAG) and VR50 (5'-TTCCCGAAGGCGTTTCTTGA) as well as primers VR51 (5'-AGCTCGACTTGGGTTCCATC) and VR52 (5'-CAGATCAGGTCGCAGCAAAG), which are specific for the orf $_{6603}$ and res $_{6603}$ regions, respectively, were used to screen for the presence of Tn6603 in P. aeruginosa clinical strains. In addition, to identify the presence of Tn6603 or Tn6603::Tn nested elements in the chromosomal orfX gene of the clinical strains, primers VR131 (5'-ATGAAGCAGACCTTCGAATA) and VR135 (5'-CGCCATTGTGTTGTGGAACA) as well as primers VR132 (5'-TTATGAGGTTGCGCGCTTG) and VR136 (5'-GCCATCACGCTCCAGTAACT) were used. These primer-pairs amplify the orfX-tnp $A_{6603}(304 \mathrm{bp})$ and orf41 6603 -orfX (520 bp) junction fragments, respectively. Primer pairs used for strain construction (VR56/VR67 and VR75/VR76) are shown in Table 1. Plasmid DNA was isolated from $10 \mathrm{~mL}$ overnight NB cultures. DNA from P. aeruginosa PA65 and strains listed in Table 2 was obtained using the Wizard genomic extraction kit (Promega, Alexandria, NSW, Australia); the QIAprep Spin Miniprep Kit (Qiagen, Chadstone, VIC, Australia) was used to screen for plasmid DNA in clinical strains, or to isolate pUB307/pUB1601 plasmids carrying res site hunter or nested transposons, both according to the manufacturers' instructions. DNA libraries were prepared for sequencing using the Nextera ${ }^{\circledR}$ XT V2 DNA library preparation kit (Illumina, San Diego, CA, USA) according to the manufacturer's instructions. DNA sequencing was performed using a 300 bp paired-end reads Miseq ${ }^{\circledR}$ V3 reagent kit (300 cycles) (Illumina, San Diego, CA, USA) on an Illumina MiSeq ${ }^{\circledR}$ (Illumina, San Diego, CA, USA). De novo assembly of the sequenced reads were conducted using CLC Workbench (version 9.5.1, CLC bio, a QIAGEN Company, Prismet, Aarhus, Denmark) or Unicycler [47]. Gene annotation was manually performed using the Glimmer Prediction tool on Geneious Prime ${ }^{\circledR}$ (version 2019.0.3, Biomatters, Ltd., Auckland, New Zealand). Gene sequences were confirmed using BLAST NCBI. 
Table 1. Bacterial plasmids used.

\begin{tabular}{|c|c|c|}
\hline Plasmid ${ }^{a, b}$ & Relevant Features or Derivations & Reference/Source \\
\hline \multicolumn{3}{|l|}{ Conjugative Plasmids } \\
\hline pUB307 & $\begin{array}{c}\mathrm{Ap}^{\mathrm{s}} \text { deletant of RP1; has parA-res }{ }_{\text {IncP }} \text { region; } \mathrm{Tc}^{\mathrm{r}} \\
\mathrm{Km}^{\mathrm{r}}\end{array}$ & [48] \\
\hline pUB1601 & $\begin{array}{c}\text { PstI-ligation derivative of } \mathrm{RP} 1 \text {; lacks parA-res }{ }_{\text {IncP }} \\
\text { region; } \mathrm{Tc}^{\mathrm{r}} \mathrm{Km}^{\mathrm{r}}\end{array}$ & [49] \\
\hline pSP116 ${ }^{\mathrm{c}}$ & pUB1601tet::Tn6603c; $\mathrm{Km}^{\mathrm{r}} \mathrm{Cm}^{\mathrm{r}}$ & This work \\
\hline pSP144 & pUB1601tet:: $\Omega 1 T n 502 ; \mathrm{Km}^{\mathrm{r}} \mathrm{Hg}^{\mathrm{r}}$ & [37] \\
\hline pSP145 & pUB1601tet::Tn501; $\mathrm{Km}^{\mathrm{r}} \mathrm{Hg}^{\mathrm{r}}$ & This work \\
\hline \multicolumn{3}{|l|}{ Nonconjugative Plasmids } \\
\hline pBluescript II SK+ (pSK) & E. coli vector; $\mathrm{Ap}^{\mathrm{r}}$ & Stratagene \\
\hline pACYC184 & E. coli vector; $\mathrm{Cm}^{\mathrm{r}} \mathrm{Tc}^{\mathrm{r}}$ & [50] \\
\hline pBR322 & E. coli vector; $\mathrm{Ap}^{\mathrm{r}} \mathrm{Tc}^{\mathrm{r}}$ & [51] \\
\hline pVS76 (pBR322-res IncP) & $\begin{array}{l}\text { pBR322 with bla disrupted by a clone of the RP1 } \\
\text { parA-res IncP region; } \mathrm{Tc}^{\mathrm{r}}\end{array}$ & [52] \\
\hline pVS982 & pBR322::Tn501; $\mathrm{Ap}^{\mathrm{r}} \mathrm{Tc}^{\mathrm{r}} \mathrm{Hg}^{\mathrm{r}}$ & [53] \\
\hline pVS983 & pBR322tet::Tn502; $\mathrm{Ap}^{\mathrm{r}} \mathrm{Hg}^{\mathrm{r}}$ & [53] \\
\hline pSP111 d (pSK-Tn6603) & $\begin{array}{c}\text { pSK with a clone of Tn6603 from P. aeruginosa } \\
\text { PA65; } \mathrm{Ap}^{\mathrm{r}}\end{array}$ & This work \\
\hline pSP112 e (pSK-Tn6603c) & $\begin{array}{l}\text { pSP111 with a clone of the cat gene from } \\
\text { pACYC184; } \mathrm{Ap}^{\mathrm{r}} \mathrm{Cm}^{\mathrm{r}}\end{array}$ & This work \\
\hline pSP114 ${ }^{\mathrm{f}}\left(\mathrm{pBR} 322-\mathrm{res}_{6603}\right)$ & $\begin{array}{l}\text { pVS76 with parA-res IncP sequences removed and } \\
\text { replaced with tnpA-orf-res region of Tn } 6603 ; \mathrm{Tc}^{\mathrm{r}}\end{array}$ & This work \\
\hline \multicolumn{3}{|c|}{ 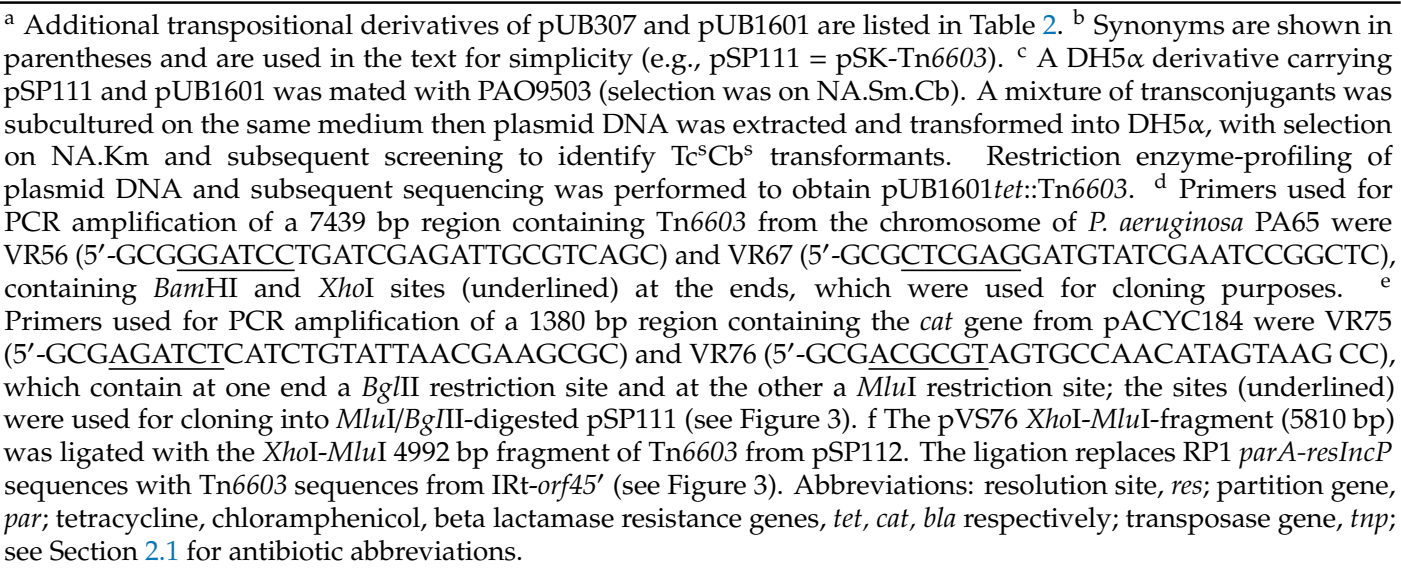 } \\
\hline
\end{tabular}

Table 2. Identification of Tn5053 family transposons and their carrier transposons in mercury(II)resistant clinical strains of $P$. aeruginosa.

\begin{tabular}{|c|c|c|c|c|}
\hline $\begin{array}{l}\text { P. aeruginosa } \\
\text { Strain }\end{array}$ & Year Isolated ${ }^{a}$ & $\begin{array}{l}\text { Transfer Frequency to } \\
\text { pUB307; Tn Detected }{ }^{\text {,g }}\end{array}$ & $\begin{array}{l}\text { Transfer Frequency to } \\
\text { pUB1601; Tn Detected }{ }^{f, h, i}\end{array}$ & $\begin{array}{c}\text { Location of } \\
\text { Nested Tn (or Tn) } \\
\text { in Clinical Strain } \mathbf{j}\end{array}$ \\
\hline RH19 & $1992^{b}$ & $6.2 \times 10^{-3} ; \operatorname{Tn} 502$ & $1.6 \times 10^{-6} ; \operatorname{Tn} 6603:: \operatorname{Tn} 502$ & $\Omega 1$ \\
\hline AW32 & $1991^{c}$ & $7.2 \times 10^{-3} ; \operatorname{Tn} 502$ & $3.2 \times 10^{-8} ; \operatorname{Tn} 6603:: \operatorname{Tn} 502$ & $\operatorname{orf} \mathrm{X}$ \\
\hline AW57 & $1991^{c}$ & $1.1 \times 10^{-3} ; \operatorname{Tn} 502$ & $1.2 \times 10^{-8} ; \operatorname{Tn} 502$ & $\Omega 2$ \\
\hline PA9 & $2015^{d}$ & $2.8 \times 10^{-2} ; \operatorname{Tn} 502$ & $2.0 \times 10^{-8} ; \operatorname{Tn} 502$ & $\Omega 3$ \\
\hline AW54b & $1991^{c}$ & $2.5 \times 10^{-4} ; \operatorname{Tn} 512$ & $<1.0 \times 10^{-8} ; \mathrm{ND}$ & $\Omega 4$ \\
\hline AW60 & $1991^{c}$ & $1.6 \times 10^{-4} ; \operatorname{Tn} 512$ & $<1.0 \times 10^{-8} ; \mathrm{ND}$ & $\Omega 4$ \\
\hline PA8 & $2015^{d}$ & $1.6 \times 10^{-4} ; \operatorname{Tn} 5053$ & $1.0 \times 10^{-5} ; \operatorname{Tn} 6603:: \operatorname{Tn} 5053$ & $\operatorname{orf} X$ \\
\hline PS1 & $1988^{\mathrm{e}}$ & $0.5 \times 10^{-4} ; \operatorname{Tn} 5053$ & $7.0 \times 10^{-6} ; \operatorname{Tn} 6603:: \operatorname{Tn} 5053$ & $\operatorname{orf} X$ \\
\hline AB1 & $1992^{c}$ & $1.2 \times 10^{-4} ; \operatorname{Tn} 5053$ & $3.4 \times 10^{-6} ; \operatorname{Tn} 6603:: \operatorname{Tn} 5053$ & $\operatorname{orf} X$ \\
\hline AW1 & $1991^{c}$ & $0.6 \times 10^{-4} ; \operatorname{Tn} 5053$ & $1.0 \times 10^{-5} ; \operatorname{Tn} 6603:: \operatorname{Tn} 5053$ & $\operatorname{orf} X$ \\
\hline
\end{tabular}


Table 2. Cont.

\begin{tabular}{ccccc}
\hline $\begin{array}{c}\text { P. aeruginosa } \\
\text { Strain }\end{array}$ & Year Isolated a & $\begin{array}{c}\text { Transfer Frequency to } \\
\text { pUB307; Tn Detected f,g }\end{array}$ & $\begin{array}{c}\text { Transfer Frequency to } \\
\text { pUB1601; Tn Detected f,h,i }\end{array}$ & $\begin{array}{c}\text { Location of } \\
\text { Nested Tn (or Tn) } \\
\text { in Clinical Strain }{ }^{j}\end{array}$ \\
\hline PA118 & $2015^{\mathrm{d}}$ & $1.2 \times 10^{-2} ; \operatorname{Tn} 5058 v 2$ & $1.2 \times 10^{-6} ; \operatorname{Tn} 1013^{\#}:: \operatorname{Tn} 5058 v 2$ & $\Omega 5$ \\
PA41 & $2015^{\mathrm{d}}$ & $2.9 \times 10^{-5} ; \operatorname{Tn} 6604$ & $3.0 \times 10^{-7} ; \operatorname{Tn} 6603:: \operatorname{Tn} 6604$ & orfX \\
\hline
\end{tabular}

${ }^{a}$ The strains listed hybridized to a tni $_{502}$ probe. Two others had a truncated tniA gene and were $\mathrm{Hg}(\mathrm{II})$-sensitive; they were not studied further. None of the listed strains produced transconjugants on NA.Sm.Hg $\left(<10^{-8} /\right.$ donor $)$ when mated with $43{ }^{\circ} \mathrm{C}$-grown PAO9503. ${ }^{b, c, d}, \mathrm{e}$ Indicating clinical source of the strains. ${ }^{\mathrm{f}}$ Represents the recovery of $\mathrm{Hg}(\mathrm{II})$-resistant transconjugants per donor. The clinical strains carried pUB307 or pUB1601; the recipient was PAO9503. ${ }^{\mathrm{g}}$ The transposons were inserted in the pUB307 res region within position 35,014-35,020 (accession no. BN000925) in resII. All are $99-100 \%$ identical to the previously named prototypes, except for the new transposon, Tn6604, and Tn5058v2 (see text). ${ }^{\mathrm{h}}$ The nested transposons were inserted in pUB1601 at positions near oriV, klaC, $k l c B, k l a B$, and $k o r C$. In matings involving AW57 and PA9 donors, Tn502 alone transposed to pUB1601. ${ }^{\mathrm{i}}$ The Tn6603 sequences were identical, except for a single base-pair difference in Tn6603 from strain PA8. Tn1013\# from strain PA118 is related to the prototype Tn1013 [54] (see text). ${ }^{j}$ Tn6603-nested elements were inserted in orf X (see text), except for in strain RH19. Symbols $\Omega 1-\Omega 5$ indicate insertions at different chromosomal sites. The latter were determined from contigs that included the res site hunter (Tn502 or Tn512) or nested element (Tn6603::Tn502 or Tn1013 $::$ Tn5058v2) and 3.0-7.0 kb of chromosomal DNA on each flank. DRs adjoined Tn6603 in $\Omega 1$ (CACAT), Tn502 in $\Omega 2$ (TAATT), and Tn1013\# in $\Omega 5$ (TGAAT). The $\Omega 1-\Omega 4$ insertion sites were within hypothetical genes or between such genes, except for $\Omega 5$, which was within an orf encoding a membrane fusion protein efflux pump. $\mathrm{ND}=$ not detected.

\subsection{Nucleotide Sequence Accession Numbers}

Nucleotide sequences accession numbers of mobile elements deposited in GenBank are as follows: Tn6603 (MT043136), Tn6604 (MT043137), Tn5058v2 (MT043138), and Tn1013\# (MT043138). The accession numbers of sequences used for comparative studies are: Tn1013 (AM261760) and RP1 (BN000925). Others are listed in figure descriptions. Accession numbers of GenBank sequences containing Tn6603 or Tn6603 with inserted res site hunter transposons are shown in Table S1.

\section{Results}

\subsection{Isolation of Res Site Hunter Transposons, Including the New Element Tn6604, from Clinical Strains of $P$. aeruginosa}

We studied 191 P. aeruginosa strains obtained from hospitals in Melbourne in the period 1988-2015. Fourteen strains were found to hybridize with a probe $\left(\operatorname{tni}_{502}\right)$ of the Tn502 transposase gene, of which 12 were mercury-resistant $\left(\mathrm{Hg}^{\mathrm{r}}\right)$. Each of the latter group carried a presumptive Tn502-related mer transposon, probably chromosomal, as no plasmid DNA was detected, nor was $\mathrm{Hg}$ (II) resistance transferable to a recipient strain (PAO9503) by conjugation (Table 2 and footnote a).

To recover transposons, plasmid pUB307 was used as a "bait", as it carries a target site (parA-res IncP) favored by res site hunters (Table 1) $[19,21,37,53]$. When pUB307 was passaged through the 12 strains and then to strain PAO9503, all yielded pUB307- $\mathrm{Hg}^{\mathrm{r}}$ plasmids (at ca $10^{-2}-10^{-5} /$ donor; Table 2). One plasmid from each strain, when sequenced, was found to have a res site hunter transposon inserted in the $\operatorname{res}_{\text {IncP }}$ sequence (Table 2 and footnote g) and oriented with the IRo-end adjacent to parA. Ten of the transposons were identical (99-100\%) to prototype elements: namely, to Tn502 [22], Tn512 [22], and Tn5053 [21] (Table 2). Another transposon, Tn5058v2, was identical to the prototype Tn5058 [26], except for having an extra gene remnant (mer $A 2^{\prime}, 229$ bp) (Figure 1). All eleven transposons had a simple structure consisting of mer genes and tni genes bounded by 25 bp IRs (Figure 1). 


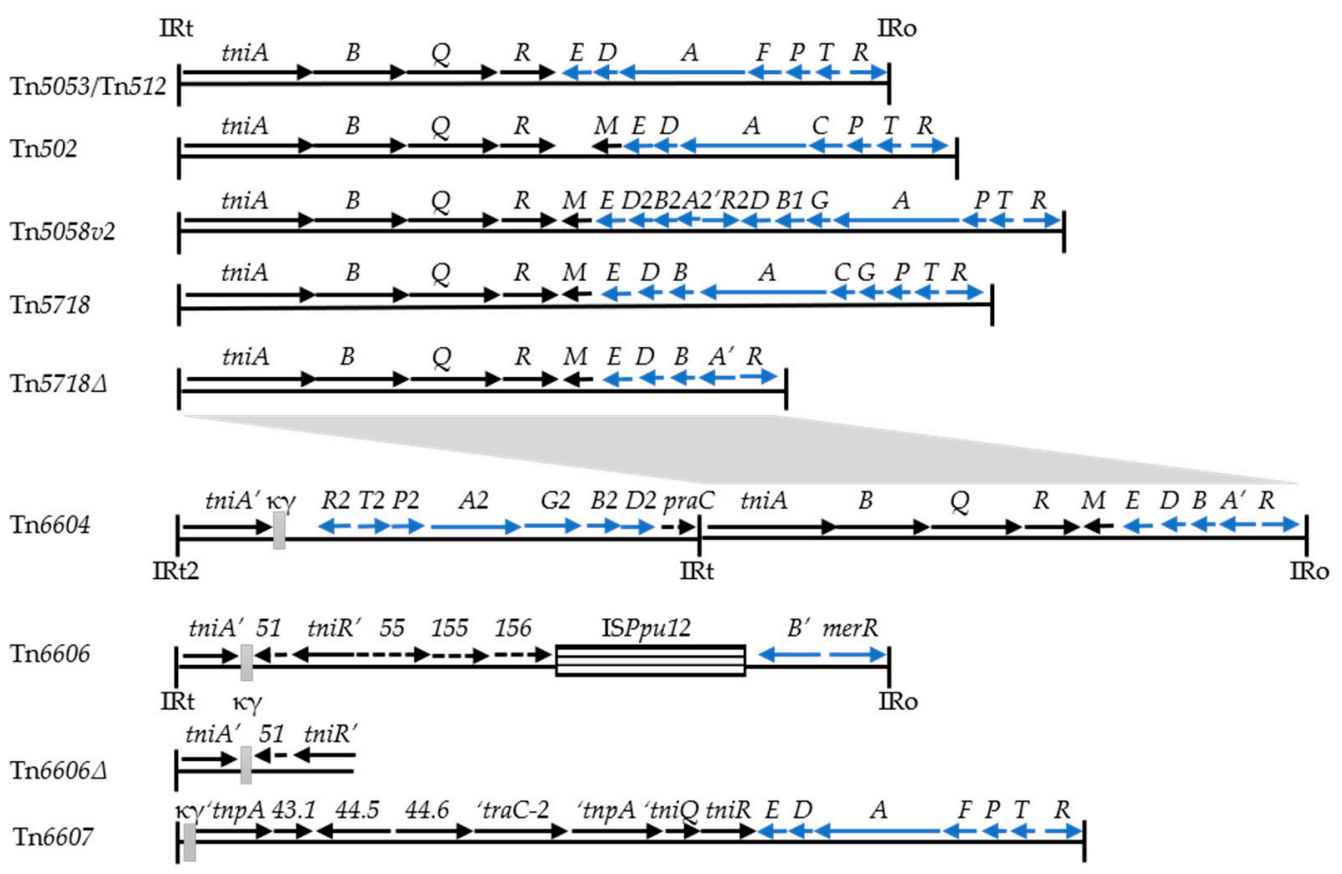

Figure 1. Structures of Tn5053 family transposons. The transposition genes ( $t n i$ and $\operatorname{tnp}$ ), the mercury resistance genes(mer) and hypothetical genes (orfs) are represented as named or numbered arrows; remnant genes are indicated by prime notation (e.g., tni $A^{\prime}$ ) and phosphoribosyl-AMP cyclohydrolase by praC. The positions of IRs ( $25 \mathrm{bp}$ ) are shown, and inserted MGEs are represented as boxes. Identity (95\%) between Tn5718 $\Delta$ and Tn6604 is indicated by the grey box. Putative products of the orfs are described in Figure 5a and by Haines et al. [24] for Tn6607. The Figure was generated from the following GenBank entries: Tn5053 (L40585); Tn502 (EU306743); Tn512 (EU306744); Tn5718 (AJ304453); Tn57184 (AM261760); Tn6606 (AJ344068); Tn6606 (KF743817); Tn6607 (previously unnamed; AM157767).

In contrast, the last transposon, named Tn6604 (14,858 bp), consisted of three discrete parts (Figure 1), each probably from a different interacting element (Figure 2). The right arm of Tn6604 (7176 bp) is $95 \%$ identical to Tn $5718 \Delta$ detected in a P. aeruginosa IncP-1 $\alpha$ plasmid [54]. Tn $5718 \Delta$ has an incomplete mer module, but its tni module and terminal IRs are intact. The central portion of Tn6604 (6399 bp) shares high identity (99\%) with the chromosomal mer region of P. putida DLL-E4 (accession no. CP007620). The same mer genes occur in mer 2 variants of Tn5041, a Tn3 family transposon detected in P. putida and P. fluorescens strains [55]. The P. putida DLL-E4-related sequences in Tn6604 terminate in the miniature element $\mathrm{k} \Upsilon(262 \mathrm{bp})$ [56]. The short left arm of Tn6604 (1284 bp) is 99\% identical to $\operatorname{Tn} 5718 \Delta / \operatorname{Tn} 5718$ [54,57]. It consists of a tniA remnant (1141 bp), directly flanked by $\mathrm{k} \Upsilon$ and by intergenic sequences adjoining the terminal IRt2 (Figure 1). Our ability to detect pUB307::Tn6604 plasmids relied upon the expression of Tn6604 transposition functions (IRt2, tni genes, IRo) and mer2 resistance functions distributed across the three parts (Figure 2). The Tn5718 $\Delta$-like component of Tn6604 is also presumably self-mobile, since it encodes the tni functions and its IRt1 is identical to IRt2 of Tn6604 (Figure 1).

The various mer-type res site hunters identified here, and including the previously reported Tn512 [22], are the first described instances in bacterial strains from Australia. This is despite their presence in clinical P. aeruginosa strains as early as 1988-1991 (Table 2). Their detection is significant because, to our knowledge, similar surveys of clinical localities elsewhere have not been reported. 


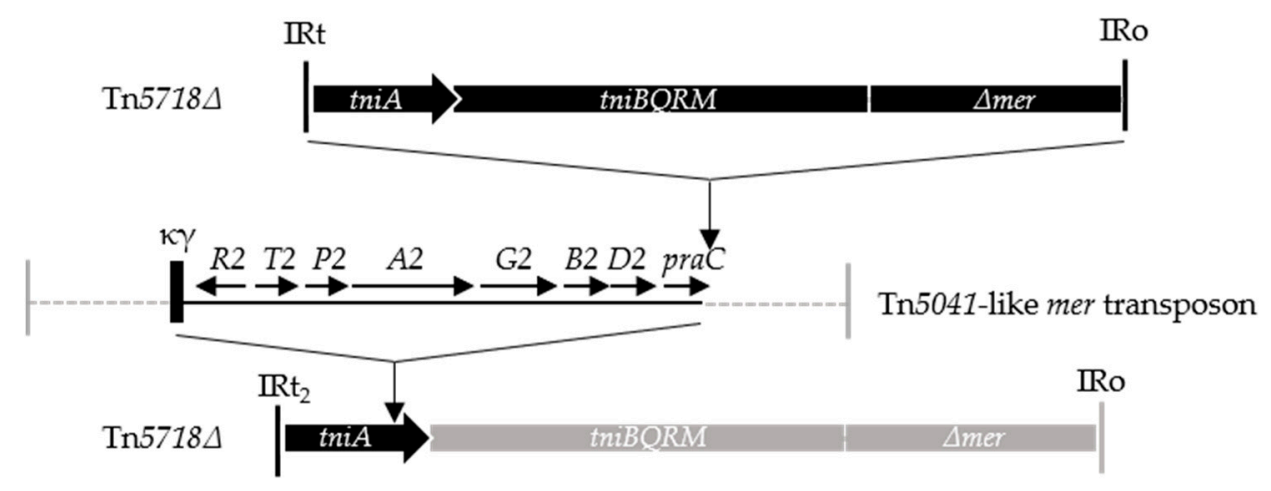

Figure 2. Hypothetical genesis of Tn6604. Three events are envisaged (see Figure 1 and text). A Tn5718 $\Delta$-like element was disrupted by a Tn5041-like mer transposon; subsequently, $\mathrm{k} \gamma$-mediated deletion fused $\mathrm{k} \Upsilon$-merR-praC sequences to the IRt2-tniA' remnant. A Tn5718 $\Delta$-like element inserted into the Tn5041 entity to the right of praC. Tn6604, bordered by IRt 2 and IRo, is shown in dark shading; grey shading represents regions absent from Tn6604. Here, $\Delta$ mer represents an incomplete mer module (see Figure 1).

\subsection{Isolation of Res Site Hunter Transposons Nested with a Carrier Transposon}

Our detection of res site hunter transposons (Table 2) relied on the established affinity of such elements for the plasmidal parA-res IncP region $[34,35,37,53]$. However, transposon-encoded res regions can also serve as suitable targets $[19,41,58]$. To detect nested associations of a res site hunter in res of a carrier transposon, we employed pUB1601 as the "bait" (Table 1). This plasmid lacks parA-res IncP, thereby limiting acquisition of a res site hunter [37], whilst allowing acquisition via a carrier element.

Plasmid pUB1601 was passaged through the 12 strains that harbored a res site hunter transposon, followed by outcrossing to PAO9503 to recover pUB1601- $\mathrm{Hg}^{\mathrm{r}}$ recombinants. This strategy was successful from ten strains, although at lower frequencies (ca $10^{-5}-10^{-8} /$ donor) than in the experiments involving pUB307 (Table 2). A plasmid from each of the ten experiments was sequenced. Two (from strains AW57 and PA9) were pUB1601::Tn502 plasmids. These represent examples of rare, random insertion events noted previously with Tn502 [37] (Table 2, footnote h). In the remaining eight, the res site hunter (Tn502, Tn5053, Tn5058v2, or Tn6604) was inserted in one of two carrier transposons, forming a larger nested arrangement. The nested transposon was at different locations in pUB1601 (Table 2, footnote h).

In the case of Tn5058v2, the carrier transposon was a close relative of Tn1013 (accession no. AM261760). It was denoted Tn1013" for discussion purposes. Tn1013 ${ }^{\#}(7875 \mathrm{bp})$ and Tn1013 (7800 bp) share high identity (99\%) across their tnpAR-res modules, which are related to transposons in the Tn21/Tn501 family. Their associated cargo genes (orf $A B C D$ ) are less similar (ca 94\% identity) and the orfC of Tn1013 is longer by $75 \mathrm{bp}$. Putative functions have been ascribed to orf $A B C D$, but no associated phenotypes are known (Figure 3). Tn5058v2 was inserted in res $1013 \#$ (near resIII; Figure 3) and was flanked by $5 \mathrm{bp}$ DRs (TGAAT), indicating that the nested structure arose from a direct transposition event. The association between $\operatorname{Tn} 1013^{\#}$ and $\operatorname{Tn} 5058 v 2$ is the first description of a mer-type res site hunter in a Tn1013-like carrier. This contrasts with at least six descriptions of Tn1013-like carriers bearing class 1 integrons (i.e., Tn1403 and Tn1404* [59], Tn6001 [60], Tn6060 [61] and Tn6061 [62], all from clinical P. aeruginosa strains, and Tn5045 [41], from a Pseudomonas permafrost strain). With one exception (Tn6061), the respective integrons are tni-defective, but retain their $\mathrm{IR}_{25}$ borders. All are inserted within res 1013 (Figure 3) and three (Tn1403, Tn1404*, and Tn5045) are flanked by 5 bp DRs. These features suggest that at least for the latter three cases, and probably for all, the integron transposed directly into Tn1013 assisted by tni functions present in trans. Similar transposition of In0 and In2 has been demonstrated experimentally [37]. 


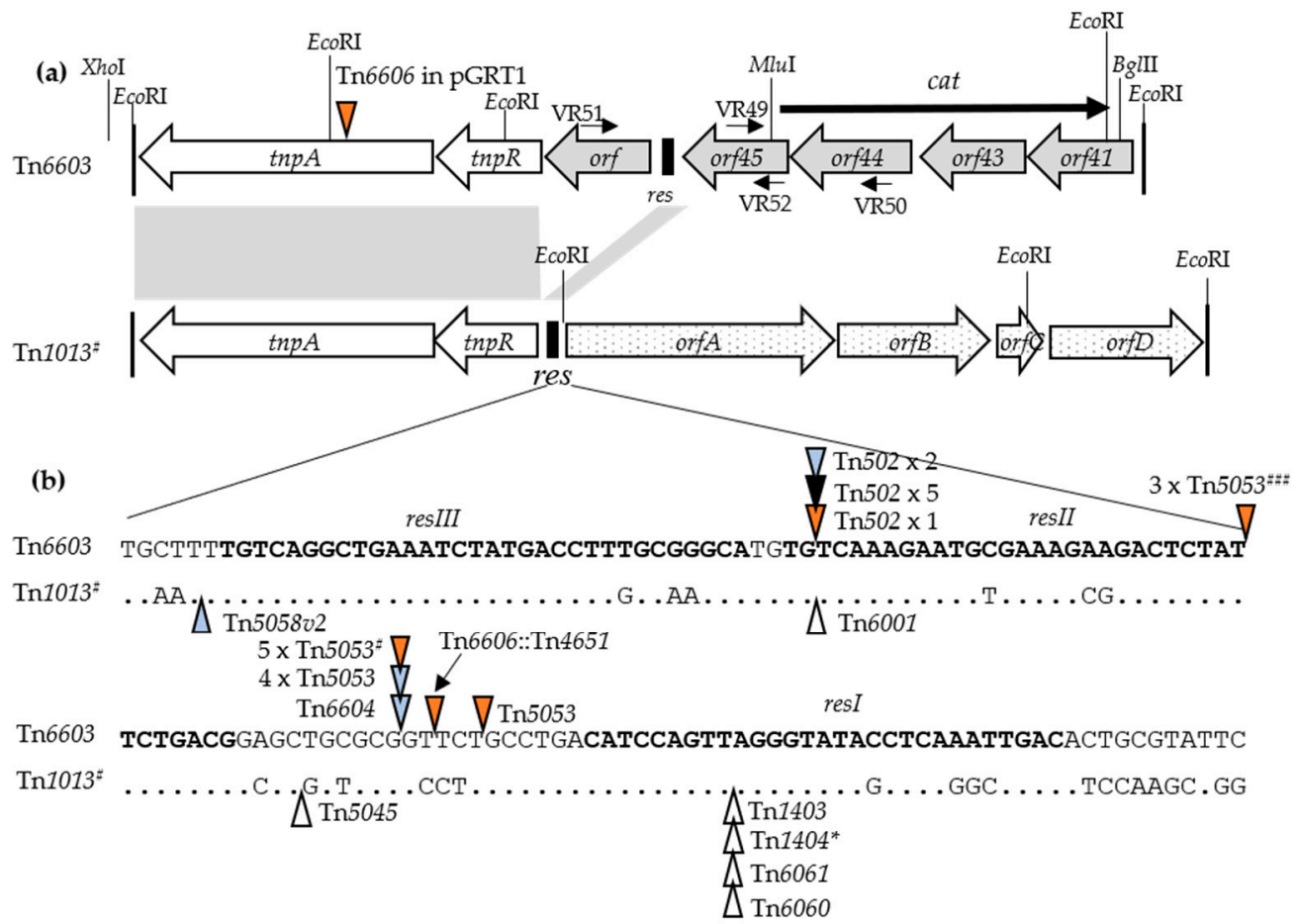

Figure 3. (a) Structures of Tn6603 and Tn1013 ${ }^{\#}$ : The tnp genes and orfs are represented as arrows and the res sites as black boxes. The positions of IRs ( $38 \mathrm{bp})$ are indicated by vertical lines; some include EcoRI sites. The cat gene in Tn6603c is shown overlying the orfs it replaces in Tn6603. Identity (92\%) between the tnp regions is indicated by grey boxes. The locations of primers pairs (VR49/VR50 and VR51/VR52) used in PCRs, and of restriction enzyme sites used for strain construction, are shown. Putative products of the cargo genes are: Orf41, cupin transcriptional regulator; Orf43, TetR/AcrR family transcriptional regulator; Orf44, NAD(P)-dependent oxidoreductase; Orf45, osmotically induced detox protein; Orf, unknown; OrfA, sodium-independent anion transporter; OrfB, universal stress protein UspA; OrfC, molecular chaperone DnaK; OrfD, DNA binding protein (as annotated in accession no. NC_003350 and KY494864). (b) Sequence of the res region of Tn6603 and Tn1013 ${ }^{\#}$ and transposon insertion sites: The resIII, resII, and resI sequences are shown in bold. Periods represent nucleotides identical to those in Tn6603. Triangles represent insertion sites of res site hunter transposons. Color coding is as follows: Blue, transposons shown in Table 2. All are in orfX::Tn6603 strains except for one Tn502 and one Tn5058v2 strain. Orange, transposons from GenBank sequences. All are in orfX::Tn6603 strains except for four Tn5053 strains (marked by \#). For Tn6606 and Tn6606::Tn4651, see Figure 5. White, integrons from GenBank sequences. Black, laboratory-derived independent insertions (this study).

In the case of the nested associations involving Tn502, Tn5053, and Tn6604, a new carrier element was identified and named Tn6603 (7315 bp) (Table 2, footnote i). Tn6603, as with Tn1013, is a member of the Tn21/Tn501 family. However, the $\operatorname{tnp}_{6603}$ module shares only $92 \%$ identity with the $\operatorname{tnp}_{1013}$ module, while in Tn6603, tnpR is separated from res by a putative 465 bp orf of unknown function (Figure 3). Additionally, Tn6603 contains a cargo of four genes, which are different from those in Tn1013 and transcribed in the opposite direction. Genes similar to those in Tn6603 (99\% identity) occur in Tn4653, a catabolic transposon in P. putida plasmid pWW0 [63]. Putative functions have been ascribed to the genes (named orf41-43-44-45) but are not associated with a known phenotype (Figure 3). In each nested element, the mer transposon was inserted in res 6603 (in resII for Tn502 and the same site between resI and resII for Tn5053 and Tn6604; Figure 3) and was flanked by 5 bp DRs (ATGTG and GCGCG, respectively). This indicates that the transposon inserted into the Tn6603 carrier on at least three separate occasions. Figure 3 shows the sequences of res $_{6603}$ and res $1013 \#$ and the distribution of insertion sites for the mer 
transposons reported here and the integrons reported by others. Most insertions cluster in the resI-resII region, whereas Tn502 insertions are at a single, more distant resII site, while Tn5058v2 is near resIII.

\subsection{Isolation and Characterization of the Carrier Transposon Tn6603}

Tn6603 was linked with Tn502, Tn5053, or Tn6604 in seven of the surveyed strains (Table 2). To detect instances of the "unloaded" Tn6603, the strain collection was subjected to PCR analysis using

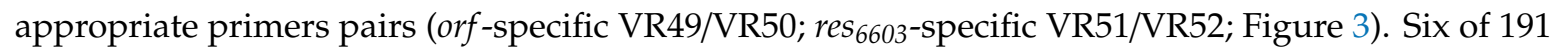
strains, all $\mathrm{Hg}(\mathrm{II})$-sensitive, yielded products in the expected size ranges (i.e., $871 \mathrm{bp}$ and $1095 \mathrm{bp}$, respectively). One strain ( $P$. aeruginosa PA65) was sequenced, revealing a single chromosomal copy of Tn6603 (7315 bp) flanked by 5 bp DRs (ACCAA). This suggested that Tn6603 had inserted at that site by direct transposition. Tn6603 was PCR-amplified (using primers VR56/VR67) and the product was cloned into pBluescript SK+, forming pSP111. Further study of Tn6603 was conducted using Tn6603c (9474 bp), which has a chloramphenicol resistance gene replacing orf41-44 (Table 1; Figure 3).

Experimentally, Tn6603c was found to relocate from pBluescript SK+ to pUB1601 (and to pUB307) at frequencies of ca $1.2 \times 10^{-3}$ /donor in the absence of host RecA function (see Materials and Methods). Only resolved products were detected (e.g., pUB1601::Tn6603c plasmids) and Tn6603c was inserted at different sites in the plasmid backbone (near ori, korC, $k l a C$, and $k l a B$ ), in each instance flanked by 5 bp DRs. Thus, Tn6603c is a functional transposon with low-level target specificity. Conductional studies to identify cointegrate formation were also performed, comparing Tn6603c with Tn501, which moves by replicative transposition [5]. Transfer of pBR322 (which lacks an oriT) was mediated both by pUB1601tet::Tn6603c and pUB1601tet::Tn501 (at $2.0 \times 10^{-4} /$ donor and $3.5 \times 10^{-3} /$ donor, respectively) (see Materials and Methods). These findings demonstrate that the transposition of Tn $6603 \mathrm{c}$ involves a cointegrate intermediate.

Lastly, we used Tn502 to affirm that the various nested combinations in the clinical strains (Table 2) arose by transpositional targeting to the res 6603 site. Plasmid pUB1601tet::Tn502 served as the transpositional donor in a strain also carrying either pBR322-res 6603 (i.e., with the tnpR-res $_{6603}$ region) or

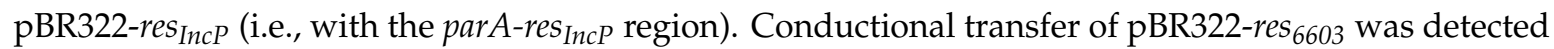
at a frequency of $2.1 \times 10^{-6}$ /donor compared to $4.4 \times 10^{-5} /$ donor for pBR322-res IncP $_{\text {(see Materials }}$ and Methods). The resolved pBR322 components from independent experiments were isolated and sequenced. In the five plasmids tested, Tn502 occurred at the same site in the resII 6603 sequence, flanked by 5 bp DRs (ATGTG); the same fusion site also occurred in the Tn6603::Tn502 transposons from strains RH19 and AW32 (Table 2; Figure 3). Tn502 also targeted the resII IncP sequence at the same relative position as in resII 6603 , but was flanked by different DRs (TTAAA) (three plasmids tested). These data confirm that the res $_{6603}$ region can serve as the target for res site hunter transposons and is favored relative to other sites in Tn6603.

\subsection{Distribution of Tn6603 and Tn6603-Nested Transposons and Their Association with Genomic Island PAGI-5v}

We detected Tn6603 in six local P. aeruginosa clinical strains and Tn6603::Tn-nested elements in seven others (Table 2). A search of the GenBank database revealed additional homologues of Tn6603, none less than $99 \%$ identity, and none named or annotated as transposons. These were 14 examples of Tn6603, one Tn6603::Tn502, and nine Tn6603::Tn5053 (Table S1). All were chromosomally located in $P$. aeruginosa strains, except for plasmid-borne instances in P. aeruginosa, P. fluorescens, and P. taiwanensis strains (1 example each). The strains were from diverse locations (e.g., UK, Europe, USA, Mexico, Hong Kong, and Kuwait), all but one isolated since 2010, and many (12/24) were clinical isolates. Therefore, Tn6603 in its native and enlarged forms is widely distributed, with P. aeruginosa as the predominant host.

With two exceptions, the various Tn6603-entities were flanked by 5 bp DRs and occupied nine disparate locations, consistent with the transpositional behavior observed with Tn6603c. One site was nonetheless overrepresented, with all the insertions (five of Tn6603, one of $\operatorname{Tn} 6603:: \operatorname{Tn} 502$, and 
five of Tn6603::Tn5053) at the same chromosomal position-nt61 of a hypothetical orf, here named orfX. Examination of the orfX region in our local strains (using primer pairs VR132/VR136 and VR131/VR135; see Materials and Methods) showed that six of the nested elements were also at position nt61 (i.e., Tn6603 nested with Tn502, Tn5053 or Tn6604; Table 2). The relationship between all of these strains most likely arises from a single transposition event that formed a P. aeruginosa orfX::Tn6603 common ancestor. The ancestral strain or derivatives subsequently inherited Tn502 or Tn6604 on at least one occasion each, or Tn5053 on at least three separate occasions, based on the different locations of the mer transposons in res 6603 when the GenBank sequences are included (Figure 3).

Scrutiny of the GenBank sequences that contained orfX::Tn6603 revealed that this feature was located towards one end of a large DNA segment (ca $94.4 \mathrm{~kb}$ ), which is a variant of genomic island PAGI-5 (99.4 kb), a member of the ICE family of mobile elements [3,6,64]. Both the variant island, PAGI-5v, and PAGI-5 probably share a common ancestor whose conserved backbone subsequently accumulated different exogeneous genes in novel regions NRI and NRII, as defined by Battle et al. [6] (Figure 4). These regions straddle orf30, the orfX homologue in PAGI-5. NRI of PAGI-5 and a nearby IS407 are replaced in PAGI-5v by a simple insertion of IS222 (flanked by a 3 bp DR, CCC) [65] and a pair of orfs. Part of NRII (6.2 kb) is present in both islands, with additional cargo in PAGI-5, including MGE remnants (phage-type genes and Tn5041-like mer genes). Descendants of the PAGI-5v lineage have acquired a res site hunter (forming Tn6603::Tn elements) whilst maintaining a relatively unchanged backbone. One exception is the Tn6603::Tn502 strain (Figure 4). It has an extra component in NRI, and all except $278 \mathrm{bp}$ at the start of NRII are replaced by $6.8 \mathrm{~kb}$ of novel DNA. The sequence of events responsible for these various differences and the origins of the components are unknown. We obtained DNA sequences for local strains AW32, PA8, and PA41, sufficient to confirm that they too contain the short arm of PAGI-5v (attL-Tn6603::Tn); we presume the remainder of the island is also present. Collectively, the P. aeruginosa strains that have PAGI-5 or PAGI-5v are geographically dispersed, with the island situated adjacent to either of two tRNA ${ }^{\text {Lys }}$ genes (Figure 4). The latter feature suggests a capacity for lateral movement, and has been observed experimentally for several members of the pKLC102 family, which includes PAGI-5 [66,67]. Such movement is also supported on functional grounds, since these islands and PAGI-5v (e.g., in ST395, Figure 4) encode an integrase of the DNA_BRE_C-type (Orf1 of [6]) [68]. Moreover, pKLC102, PAGI-5, and PAGI-5v have conjugation-like functions, including a coupling protein (Orf34 of [6]) and relaxase (Orf2 of [6]), which are characteristic of the $\mathrm{MPF}_{\mathrm{G}}$ and $\mathrm{MOB}_{\mathrm{H}}$-types, respectively. This integrase-MPF-relaxase combination has been described previously among ICEs [68,69]. Lastly, pilus proteins required for the conjugation mechanism of PAPI-1, and which are related to those of enterobacterial plasmid R64, have homologues in PAGI-5 (Orf80-Orf91 of [6]) and pKLC102 [70], as well as in PAGI-5v. Taken together, these various features highlight evolutionary, often module-based relationships between conjugative plasmids, GIs, and ICEs, as noted by others $[69,71,72]$. 


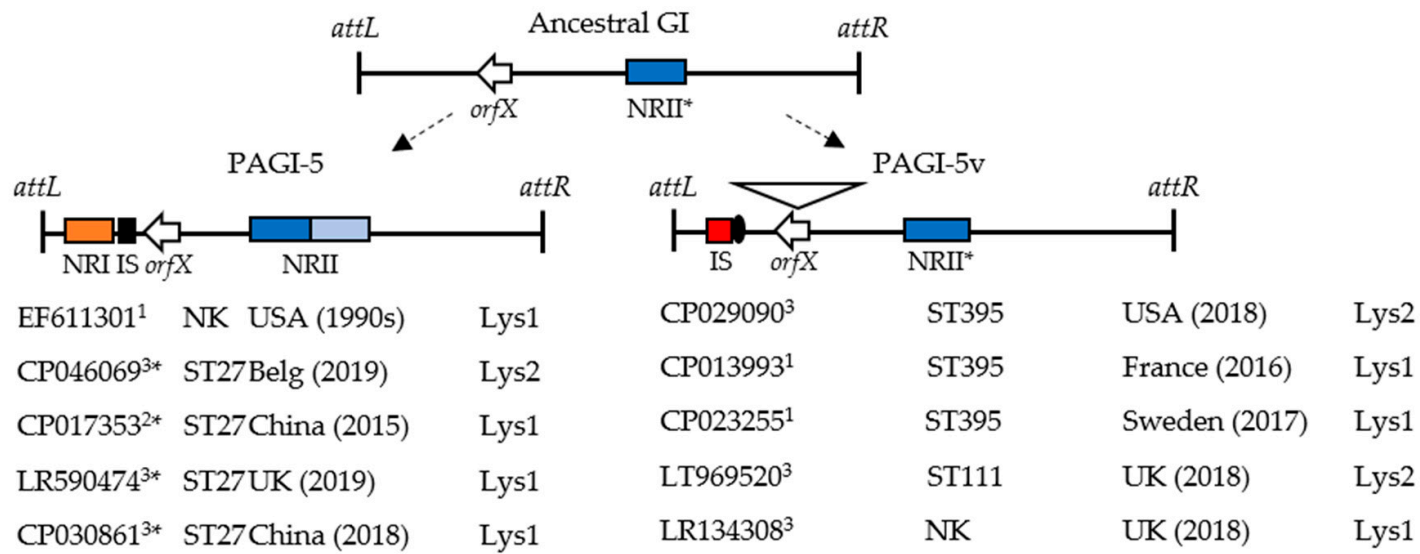

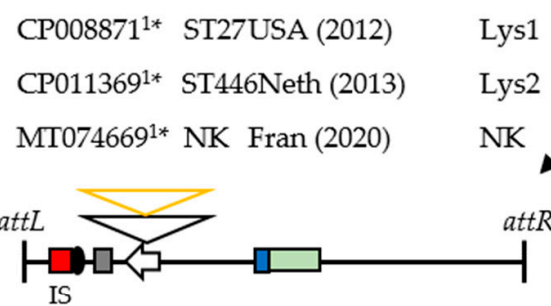

CP0303283 ST298 USA(2018) Lys1 Tn502

\begin{tabular}{lllll}
\multicolumn{2}{c}{ IS } & \multicolumn{2}{c}{ NRI* } & \\
CP008864 & ST959 & USA(2014) & Lys1 & Tn5053 \\
CP011857 & ST155 & Hong Kong(2015) & Lys2 & Tn5053 \\
CP015117 & ST155 & Netherlands(2016) & Lys2 & Tn5053 \\
CP022001 & ST155 & Mexico(2017) & Lys2 & Tn5053 \\
LR1343091 $^{1}$ & ST155 & UK(2018) & Lys2 & Tn5053 \\
AW32 $^{1}$ & NK & Aust(1991) & Lys2 & Tn502 \\
PA8 $^{1}$ & NK & Aust(2015) & Lys2 & Tn5053 \\
PA41 $^{1}$ & NK & Aust(2015) & Lys1 & Tn6604 \\
CP029605 $^{1}$ & ST235 & Colombia(2018) & Lys2 & Tn402
\end{tabular}

Figure 4. Hypothetical genesis of PAGI-5-related genomic islands in P. aeruginosa. The features shown for PAGI-5 ([6]; EF611301) and for PAGI-5v-lineages are shared by the strains listed under each figure according to accession number, sequence type (ST) (NK = not known), country of origin, date of isolation, location of the GI relative to the $\mathrm{tRNA}^{\mathrm{Lys}}$ gene copies (i.e., Lys1 $=c a 1.06 \mathrm{Mbp}$ or Lys2 $=c a$ $5.08 \mathrm{Mbp}$, see PAO1 sequence accession no. AE0040914), and the contained res site hunter transposon. For strains AW32, PA8, and PA41, sequences were obtained only for the portion covering tRNA ${ }^{\text {Lys-attL }}$ through to the orfX insertions. Symbols: ${ }^{1}$ clinical isolate; ${ }^{2}$ non-clinical isolate; ${ }^{3}$ unknown source; * lacks IS407. Distinctive features of the GIs: PAGI-5 [6] has novel regions NRI (orange box) and NRII (blue box), IS (=IS407, black box), orfX (=orf30 at nt 27,957-28,256). PAGI-5v and one-step derivatives with an inserted res site hunter transposon have IS (=IS222, red box), two orfs (black circle), orfX with inserted Tn6603 (black arrowhead), orfX::Tn6603 with inserted res site hunter (grey arrowhead), NRII* (proximal $6.2 \mathrm{~kb}$ of NRII). PAGI-5v multistep Tn502-derivative (yellow arrow head) has $1.3 \mathrm{~kb}$ novel DNA (grey box; hypothetical protein), all but 278 bp of NRII* is replaced by a $6.5 \mathrm{~kb}$ fragment containing phage-related genes (green box). The hypothetical ancestral GI has orfX and NRII*. Broken arrows indicate that multiple events have occurred to generate the descendant; solid arrow indicates a single event. Mobility-related functions are located in the following regions: orf1 integrase and orf2 $\mathrm{MOB}_{\mathrm{H}}$-type relaxase in attL-NRI; orf34 $\mathrm{MPF}_{\mathrm{G}}$-type coupling protein in orfX-NRII and orf80-orf91 pilus proteins in NRII-attR. Attachment sites, attL and attR.

\subsection{Detection of Tn6606 and Related Elements: Defective Transposons of the Tn5053 Family}

Apart from the Tn6603 and Tn6603-Tn sequences found in GenBank, we discovered two variants of Tn6603. One, named Tn6603* (6693 bp), lacks the res-associated 465 bp orf (Figure 3); it forms the base element of a complex transposon (Tn4653) in P. putida plasmid pWW0 [63] (Figure 5a). The other 
is a recombinant element, named $\operatorname{Tn} 6603 R(7672 \mathrm{bp})$. It contains a $t_{n} p_{6603}$ module associated with a different cargo module, and forms one end of a Tn4653-like transposon in P. putida plasmid pGRT1 [73]. $\operatorname{Tn} 6603^{*}$ and $\operatorname{Tn} 6603 R$ were of particular interest because their sequences are interrupted by the same mer-/tni-defective res site hunter. The defective element, named Tn6606, appears in different guises in the database, forming a family of elements. These are Tn6606 (in pGRT1 and the chromosome of P. putida W619); Tn6606::Tn4651 (in pWW0, an IncP-9 plasmid); Tn6606A, a large, possibly ancestral element present in P. stutzeri plasmid pPB; and Tn6606 $\Delta$, a remnant present in R772 (IncP-1 $\beta$ ) from a clinical Proteus strain (Figure 5b; Table 3).

(a)

$\operatorname{Tn} 6603 *$ (in Tn4653 of pWW0)

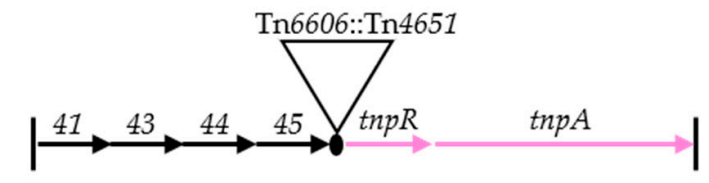

$\operatorname{Tn} 6603 R$ (in pGRT1)

$\operatorname{Tn} 501$ (in W619)

Tn501 (in pPB)
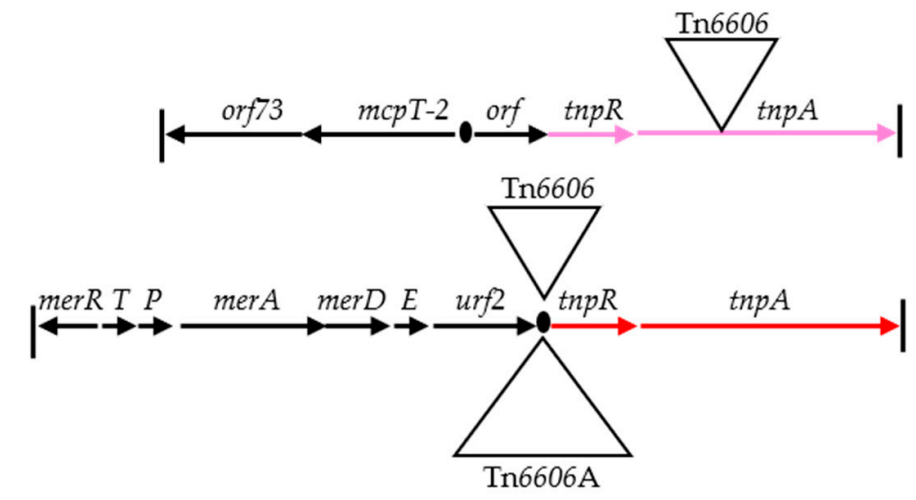

(b)

$\operatorname{Tn} 6606$

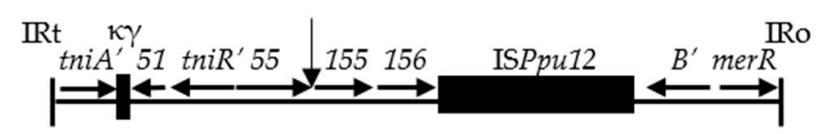

Tn6606A

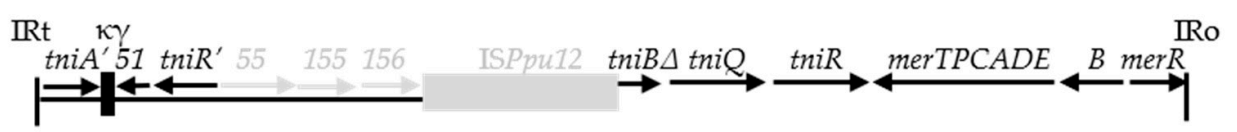

$\operatorname{Tn} 6606 \Delta$

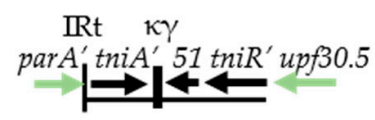

Figure 5. (a) Structures of Tn6603*, Tn6603R, and Tn501 with an inserted Tn6606 family transposon. The genes and orfs are represented as named or numbered arrows, the res sites as black circles, and the IRs (38 bp) as vertical lines. Transposition modules shown in pink ( $>99 \%$ identical) are less similar to that in red (94\% identical). Triangles show the locations of a Tn6606 family transposon. The structures shown are present in plasmids pWW0, pGRT1, pPB, and the chromosome of strain W619 (see Table 3). The putative products of orf41-orf 45 are named in Figure 3a; the mcpT-2 gene encodes a methyl-accepting chemotaxis protein and orf73 encodes a hypothetical protein. In all except in pGRT1, the res region is split into two parts by the inserted transposon. (b) Structures of Tn6606 family transposons. The positions of IRs ( $25 \mathrm{bp}$ ) are shown and remnant genes are indicated by prime notation (e.g., tni $A^{\prime}$ ). Inserted MGEs are represented as boxes, except for Tn4651, whose position in Tn6606 is marked by the vertical arrow. The region shown in grey is hypothetical, as the complete sequence of pPB is unknown. Tn6606 is present in R772 (IncP-1 $\beta$ ), whose sequences are shown in green. The putative products of the orfs encode the transcription regulator proteins (Orf51 and Orf55), putative drug resistance protein (Orf155), and putative multidrug exporter (Orf156). The figure was generated from the following GenBank entries: pWW0 (NC_003350); pGRT1 (HM626202); W619 (CP000949); pPB (U90263, U81032 and U80214); R772 (KF743817). 
Table 3. Bacterial strains that carry Tn6606 or related elements.

\begin{tabular}{cccc}
\hline Bacterium & Source (Decade) & Transposon and Carrier & Ref \\
\hline Pseudomonas putida $\mathrm{mt}-2$ & Field soil/Japan (1960) & Tn6606::Tn4651 in pWW0 (IncP-9) & {$[74]$} \\
P. putida DOT-T1E & Wastewater/Spain (1990) & Tn6606 in pGRT1 ${ }^{\text {a }}$ & {$[73]$} \\
P. putida W619 & Poplar root/stem/Belgium (2000) & Tn6606 in chromosome & {$[75]$} \\
Pseudomonas stutzeri OX & Wastewater/Italy (1980) & Tn6606A in pPB ${ }^{\text {a }}$ & {$[76]$} \\
Proteus mirabilis & Clinical isolate/USA (1970) & Tn6606 in R772 (IncP-1 $\beta)_{1}$ & {$[77]$} \\
\hline
\end{tabular}

${ }^{a}$ Unknown incompatibility type. ${ }^{b}$ Personal Communication from Dr. D. van der Lelie.

Tn6606 displays features characteristic of the Tn5053 family. It is bordered by $25 \mathrm{bp}$ IRs, which enclose remnant modules tni $A^{\prime}$ tni $R^{\prime}$, and merR mer $B^{\prime}$ (Figures 1 and $5 b$ ). The entire IRt-tni $A^{\prime}$ sequence (522 bp) and the tniR' remnant (663 bp) are most similar to those of the prototype Tn5053 $(99 \%$ and $73 \%$ identical, respectively). The sequence discrepancy, however, and the orientation of $t n i R^{\prime}$ opposite to that found typically (Figure 1) suggests that the IRt-tniA' and tniR' portions were derived from different Tn5053-like elements. The remnant mer module aligns with part of an organomercurial resistance module in $\mathrm{pPB}$ (99\% identity), hence the suggestion that Tn $6606 \mathrm{~A}$ in $\mathrm{pPB}$ may be ancestral to Tn6606. The other components of Tn6606 also suggest a complex evolutionary history. They include "orphan" genes (orf51-55-155-156; Figure 5b; [63], $\mathrm{k} \curlyvee$ [56] and the transposable ISPpu12 [78]). None of the components of Tn6606 are associated with a known phenotype.

Features at the target site of each of the Tn 6606 family members is indicative of transpositional activity. First, although these elements lack a tni module, all except Tn6606 $\Delta$ retain both IR borders, which are flanked by $5 \mathrm{bp}$ DRs. Second, each element is inserted within or close to a res site (i.e.,

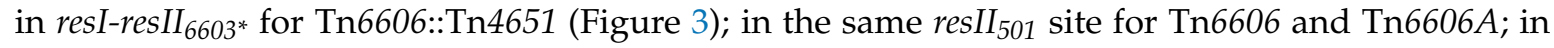
$\operatorname{tnp} A_{6603 R}$ for Tn6606; and near $\operatorname{res}_{\text {IncP }}$ for Tn6606 $\Delta$ ). Third, each element is in the typical orientation

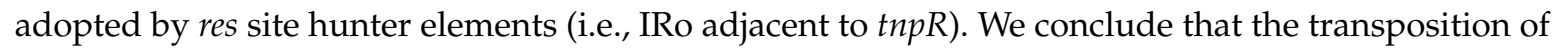
these elements to the observed sites was facilitated by tni functions provided in trans. These events occurred on at least four separate occasions involving three different res-target regions: res $_{6603}$-like, supporting observations made earlier in this report; res $_{501}$, identifying this as an alternative target site

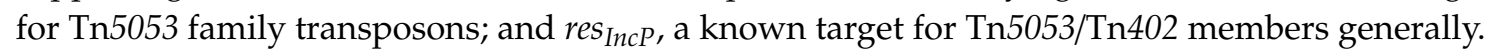

The presence of Tn6606 $\Delta$ in res IncP of R772 (IncP-1 $\beta$ ) is of interest, as it is the sole example of a Tn6606 relative outside the Pseudomonas genus and in a clinically sourced strain (Table 3). It is

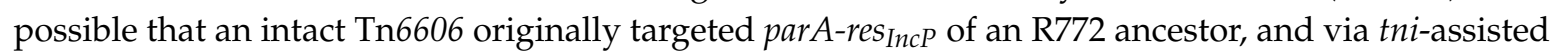
transposition miss-inserted into parA (a 264 bp remnant of par $A$ remains; Figure 5b). Subsequent recombination events, either spontaneous or caused by the activity of Tn6606 or its ISPpu12 component, resulted in deletion of Tn6606 and R772 sequences, leaving the extant structure (Figure 5b). Such losses of DNA, especially those promulgated by accrued MGEs, have been proposed to account for genetic variability, which is particularly evident in this region of IncP-1 $\beta$ plasmids $[11,79]$.

Collectively, these findings point to encounters in non-clinical environments that have enabled tni-functional elements to promote the lateral movement of tni-defective elements between MGEs. The possible participants, in this case IncP-1 plasmids, IncP-9 plasmids, and mer transposons, have been found to cohabit environments polluted by man-made or natural contaminants $[80,81]$.

\section{Discussion}

The main results from this study are that (i) members of the Tn5053 family of res site hunter elements are present in P. aeruginosa clinical strains; (ii) these res site hunters form nested associations predominantly with Tn6603, a novel carrier transposon; (iii) a historical event that linked Tn6603 with a PAGI-5-related genomic island preceded acquisition of a res site hunter on at least five subsequent occasions.

We isolated five types of Tn5053 family transposons from local hospital strains of $P$. aeruginosa (Tn502, Tn512, Tn5053, Tn5058v2, and the new element Tn6604) (Table 2, Figure 1). This substantial cohort included elements from 30-year-old strains, suggesting a long-standing association with the 
local clinical setting. All of the identified transposons had functional mer and tni modules and were chromosomally located. In most cases, this was a consequence of typical res site hunting activity directed to a carrier transposon (discussed below). However, in four strains with Tn502 or Tn512, the chromosomal locations were not linked to obvious res or resolvase gene sequences (Table 2, footnote j). In one case, Tn502 was flanked by DRs, consistent with its insertion by transposition. A similar preservation of DRs also attends chromosomal insertions of Tn5053 to non-res sites under laboratory conditions [19]. In the other three cases, DRs were absent; these were possibly deleted due to transposon activity following the insertion event, as observed with Tn502 [37]. Chromosomally inserted mer-type res site hunters in each of these two categories were found in GenBank sequences of clinical and non-clinical strains. Therefore, although res site hunters transpose only rarely in the absence of an external resolvase, such events occur in nature and may contribute to the spread of these elements more than is appreciated.

Chromosomally located Tn6603 was identified as a significant carrier of mer-type res site hunters. It was detected in the surveyed strains in its "unloaded" and nested forms (6 and 7 examples, respectively; Table 2) and in GenBank sequences (14 and 10 examples, respectively) (Table S1). $P$. aeruginosa clinical strains served almost exclusively as the hosts. In about half of the strains, the transposon was located at disparate chromosomal sites, consistent with the low-level target specificity exhibited experimentally by Tn6603c. In the remaining strains, Tn6603 (or the nested element) was located in PAGI-5v, a relative of genomic island PAGI-5 in the ICE family $[3,6,64]$. The PAGI-5v lineage was comprised of an ancestral P. aeruginosa orfX::Tn6603 strain and derivatives that later acquired a mer-type res site hunter. Strains with PAGI-5v- or PAGI-5-type islands are globally distributed, with the oldest two isolated in the 1990s (Figure 4). Some specific sequence groups are widespread (ST395, ST155, and ST27) and the islands are sited at one or other of the two chromosomal tRNA ${ }^{\text {Lys }}$ gene copies (Figure 4; [82]). This distribution suggests a capacity for lateral movement between bacteria and between integration sites, as has been demonstrated for members of the pKLC102 family, which includes PAGI-5/PAGI-5v [66,67,82]. The different locations of the res site hunter in res 6603 of PAGI-5v show that Tn5053 and Tn502 were inherited on several separate occasions, and Tn6604 was inherited once (strain PA41 is the sole example) (Table 2; Figure 3). Tn5053 occupies either of three sites in the resI-resII region of res 6603 , similar to its distribution in res of Tn1721 [19]. The middle site appears to be favored, however the nine strains have near-identical orfX::Tn6603::Tn5053 sequences and four are ST155 strains. Therefore, all nine may derive from a single Tn5053 acquisition event. In contrast, the eight examples of Tn502 in resII may identify an actual favored site, since most were independent transposition events (five isolated in this study and at least one of the remaining examples). The different targets selected by Tn5053 and Tn502 may reflect subtle differences in their transposition processes, similar to those demonstrated between Tn502 and Tn512 [37]. These data in toto identify a minimum of five occasions on which an orfX::Tn6603 strain acquired a res site hunter. The nested element in strain RH19 is not in orfX (Table 2); it may represent a sixth acquisition event or merely transposition of the element from a pre-existing orfX::Tn6603::Tn502 lineage. Whether these interactions occurred inside or outside the clinical setting and whether the first involved Tn6603 in PAGI-5v or was separate from it is not known.

Five instances of plasmid-associated Tn6603 were detected in GenBank sequences. Four involved catabolic plasmids in isolates from non-clinical sources (natural or polluted soils). Tn6603 was present in P. fluorescens plasmid pG69 (from Estonia; accession no. MH061177) and P. taiwanensis plasmid pSTY (from Germany; accession no. CP003962), whereas a minor variant, Tn6603*, occurred in pWW0 [63], while a hybrid, Tn6603R, which has different cargo genes, occurred in pGRT1 [73] (Figure 5a). Only pWW0 and pGRT1 have been characterised and both were from P. putida strains (from Japan and Belgium, respectively). These examples imply that reticulated transmission of Tn6603 occurs in nature, sometimes leading to structural changes in the transposon. Such changes were not present amongst the clinical isolates, perhaps indicating more recent occupancy in P. aeruginosa. The connection with catabolic plasmids also raises the possibility that the gene cargo in Tn6603, which 
has no demonstrated function, may provide an adaptive role in non-clinical environments. Although the catabolic plasmids are large $(117-321 \mathrm{~kb})$ and encode conjugation-like genes, only pWW0 and pGRT1 have demonstrated conjugal ability and pWW0 is in the IncP-9 group. IncP-9 plasmids have a relatively limited host range, however they are stable in several Pseudomonas species, including P. aeruginosa [63,83], and can deliver transposons across generic boundaries [84]. Therefore, transfer pathways for Tn6603 family elements from environmental Pseudomonas spp. to clinically significant $P$. aeruginosa strains can be envisaged. One example of plasmid-associated Tn6603 in P. aeruginosa has been reported (accession no. CP027175). Although the source of the strain was not specified, the plasmid $(72 \mathrm{~kb})$ encodes conjugation-like genes, therefore the potential for lateral transmission within this species already exists.

The Tn6603 variant that occurs in pGRT1 is nested with Tn6606, a mer-/tni-defective transposon that groups with several related elements (Figure 5b). A different defective transposon, also in the Tn5053 family, has been described in an IncP-1 $\Upsilon$ plasmid from river epilithon [24]. Named here as Tn6607, it retains mer $_{5053}$ and intact res-tniR $R_{5053}$ components, but is otherwise tni-defective (Figure 1). These various defective elements are all located in or near a res site (res $6603, \operatorname{res}_{501}, \mathrm{res}_{\text {IncP } \beta}$, or $\left.\operatorname{res}_{I n c P} \Upsilon\right)$ and the four that retain IR termini are flanked by 5 bp DRs. Therefore, dependence on another element to provide trans-acting tni functions operates successfully in nature to relocate defective transposons. Similar assisted relocations of class 1 integrons are identifiable among clinical strains $[15,40]$. These defective transposons typically lack the native res site, as well as tni functions, but this does not undermine cointegrate resolution, as the target site resolvase aids resolution via the host RecA system [37]. On the other hand, transposition to a site lacking an external resolvase yields long-lived cointegrates because the RecA-mediated process is inefficient. The mer-type defective elements mentioned here have complex mosaic structures, suggesting successive recombination and recruitment events. They also encode orfs that may be connected to catabolic functions, perhaps relevant to strain adaptation in natural environments. We are not aware of other defective members of the Tn5053 family.

Tn501 and Tn1013 ${ }^{\#}$ were identified as carriers of mer-type res site hunters, although examples were limited to Tn501::Tn6606 elements (Figure 5a), Tn1013 ${ }^{\#: T n 5058 v 2 ~(T a b l e ~ 2), ~ a n d ~ a ~ T n 1013:: T n 512 ~}$ sequence from a P. alkylphenolica soil isolate (accession no. CP009048). Tn501 is common in various GenBank sequences, whereas Tn1013 appeared in P. aeruginosa strains, occurring in an environmental IncP-1 $\alpha$ plasmid [54] and in plasmid and chromosomal sites in clinical strains (accession no. MN433457 and CP031677). These few associations with mer-type res site hunters are nevertheless consistent with reports of class 1 integrons in Tn1013, its relative Tn1403, and in Tn5051 and Tn1721, which have links with Tn501 [23,41,58]. These carriers and Tn6603 form two distinguishable groups based

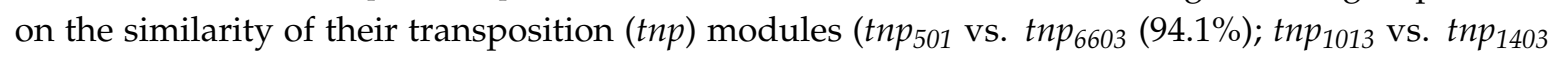
$(94.6 \%) ; t n p_{1013}$ vs. $\left.\operatorname{tn} p_{6603}(91.9 \%)\right)$ and alignment differences in a 32 bp segment that abuts the $\operatorname{tnpR}$ start codon [59]. Thus, Tn1013 (and Tn1013\# from this study) groups with Tn1403, whereas Tn501 groups with Tn6603*, the base element of Tn4653 (Figure 5a). By extension, Tn6603 (and Tn6603R) belongs to the latter group, even though its $32 \mathrm{bp}$ segment is replaced by a $465 \mathrm{bp}$ orf (Figure 3). Apart from $\operatorname{orf}_{465}$, Tn6603 and Tn6603* have identical tnp and cargo modules. A different cargo module is common to Tn1013 and Tn1403 (Figure 3; [59]). These various distinguishing features identify potential evolutionary lineages within a broadly related group of elements in the Tn21/Tn501 group.

Our experimental focus was on transposon targets of mer-type res site hunters in clinical strains. Although these had not previously been defined, possible targets were known from laboratory studies using Tn5053 [19] and the natural targets of Tn402 family members [41,58]. We can now add to the limited list of mer-sensitive transposon targets a third example involving a Tn1013-like element $\left(\operatorname{Tn} 1013^{\#}\right)$ and the new element, Tn6603, which predominated in our strains. Tn6603 was conspicuous because of its strong association with $P$. aeruginosa clinical strains beyond those tested, and because of its occurrence in PAGI-5v, an ICE whose relatives in the pKLC102 family are abundant in P. aeruginosa and can contribute to virulence [6,82,85]. Genomic islands, including examples in the ICE group, also have 
proposed roles in the prevalence and transfer of antimicrobial resistance in P. aeruginosa, often through their carriage of class 1 integrons, which may be embedded in mer-sensitive or mer-resistant transposon carriers $[17,38,61,62,64,86]$. The presence of Tn6603 in PAGI-5v, or separately in the chromosome, raises the prospect of future acquisition of class 1 integrons and their dispersal via the GI/ICE or via another MGE that acquires the Tn6603::In element or In alone. The mer-sensitive Tn4661 transposon, unrelated to Tn6603, is implicated in similar interconnected transmission routes. Tn4661 is part of PAGI-4 in P. aeruginosa C strains [87] and was found to be plasmid-borne, with an added nested integron (Tn6061), among other clinical isolates in which Tn6061 was chromosomal [62]. Class 1 integrons, although not self-mobile, can independently relocate using tni functions supplied in trans. The mer-type res site hunters that cohabit with integrons can provide these functions, either from a chromosomal location, as we found, or from a plasmid (e.g., IncP-1 $\alpha$ plasmids; [54,88]). Functional Tn402 transposons are an alternative source. We note with interest a recent example of a Tn6603::Tn402 element encoding an oxa2 gene cassette in a P. aeruginosa clinical strain from Colombia (accession no. CP029605). The strain belongs to the globally dispersed ST235 clone and our analysis identified Tn6603::Tn402 within orfX in PAGI-5v (Figure 4). We anticipate the emergence of other examples that link Tn402 family members, both the fully functional and class 1 integron types, to PAGI-5v through res-targeting of Tn6603.

Supplementary Materials: The following are available online at http://www.mdpi.com/2076-2607/8/12/1997/s1: Table S1: Strains containing Tn6603 or Tn6603::Tn in GenBank.

Author Contributions: Conceptualization, V.R., V.A.S. and S.P.; methodology, V.R., V.A.S. and S.P.; validation, V.R., V.A.S. and S.P.; formal analysis, V.R. and S.P.; investigation, V.R.; resources, S.P.; data curation, V.R.; writing—original draft preparation, V.A.S.; writing—review and editing, V.R., V.A.S. and S.P.; supervision, V.A.S. and S.P.; project administration, S.P. All authors have read and agreed to the published version of the manuscript.

Funding: Financial support for this research was provided from university funding to the department.

Acknowledgments: We thank Melanie Damtsis for DNA sequencing and analysis of the parA region of R772. Vaheesan Rajabal was the recipient of a La Trobe University postgraduate award.

Conflicts of Interest: The authors declare no conflict of interest.

\section{References}

1. Botelho, J.; Grosso, F.; Peixe, L. Antibiotic resistance in Pseudomonas aeruginosa-Mechanisms, epidemiology and evolution. Drug Resist. Update 2019, 44, 100640. [CrossRef] [PubMed]

2. Silby, M.W.; Winstanley, C.; Godfrey, S.A.; Levy, S.B.; Jackson, R.W. Pseudomonas genomes: Diverse and adaptable. FEMS Microbiol. Rev. 2011, 35, 652-680. [CrossRef] [PubMed]

3. Kung, V.L.; Ozer, E.A.; Hauser, A.R. The accessory genome of Pseudomonas aeruginosa. Microbiol. Mol. Biol. Rev. 2010, 74, 621-641. [CrossRef] [PubMed]

4. Grinsted, J.; De La Cruz, F.; Schmitt, R. The Tn21 subgroup of bacterial transposable elements. Plasmid 1990, 24, 163-189. [CrossRef]

5. Liebert, C.A.; Hall, R.M.; Summers, A.O. Transposon Tn21, flagship of the floating genome. Microbiol. Mol. Biol. Rev. 1999, 63, 507-522. [CrossRef]

6. Battle, S.E.; Meyer, F.; Rello, J.; Kung, V.L.; Hauser, A.R. Hybrid pathogenicity island PAGI-5 contributes to the highly virulent phenotype of a Pseudomonas aeruginosa isolate in mammals. J. Bacteriol. 2008, 190, 7130-7140. [CrossRef] [PubMed]

7. Hong, J.S.; Yoon, E.-J.; Lee, H.; Jeong, S.H.; Lee, K.-W. Clonal dissemination of Pseudomonas aeruginosa ST235 carrying blaIMP-6 and emergence of blaGES-24 and blaIMP-10 on novel genomic islands PAGI-15 and -16 in Korea. Antimicrob. Agents Chemother. 2016, 60. [CrossRef]

8. Kawalek, A.; Kotecka, K.; Modrzejewska, M.; Gawor, J.; Jagura-Burdzy, G.; Bartosik, A.A. Genome sequence of Pseudomonas aeruginosa PAO1161, a PAO1 derivative with the ICEPae1161 integrative and conjugative element. BMC Genom. 2020, 21, 14. [CrossRef]

9. Jacoby, G.A. Resistance plasmids of Pseudomonas. In The Biology of Pseudomonas; Elsevier BV: Amsterdam, The Netherlands, 1986; pp. 265-293.

10. Boronin, A.M. Diversity of Pseudomonas plasmids: To what extent? FEMS Microbiol. Lett. 1992, 100, $461-467$. [CrossRef] 
11. Schlüter, A.; Szczepanowski, R.; Pühler, A.; Top, E.M. Genomics of IncP-1 antibiotic resistance plasmids isolated from wastewater treatment plants provides evidence for a widely accessible drug resistance gene pool. FEMS Microbiol. Rev. 2007, 31, 449-477. [CrossRef]

12. Cazares, A.; Moore, M.P.; Hall, J.P.J.; Wright, L.L.; Grimes, M.; Emond-Rhéault, J.-G.; Pongchaikul, P.; Santanirand, P.; Lévesque, R.; Fothergill, J.L.; et al. A megaplasmid family driving dissemination of multidrug resistance in Pseudomonas. Nat. Commun. 2020, 11, 1-13. [CrossRef] [PubMed]

13. Partridge, S.R.; Recchia, G.D.; Stokes, H.W.; Hall, R.M.; Gong, Y.-F.; Robinson, B.S.; Rose, R.E.; Deminie, C.; Spicer, T.P.; Stock, D.; et al. Family of class 1 integrons Related to In4 from Tn1696. Antimicrob. Agents Chemother. 2001, 45, 2319-2326. [CrossRef] [PubMed]

14. Petrovski, S.; Stanisich, V.A. Embedded elements in the IncP $\beta$ plasmids R772 and R906 can be mobilized and can serve as a source of diverse and novel elements. Microbiology 2011, 157, 1714-1725. [CrossRef] [PubMed]

15. Domingues, S.; Da Silva, G.J.; Nielsen, K.M. Integrons. Mob. Genet. Elem. 2012, 2, 211-223. [CrossRef] [PubMed]

16. Hall, R.M. Integrons and gene cassettes: Hotspots of diversity in bacterial genomes. Ann. N. Y. Acad. Sci. 2012, 1267, 71-78. [CrossRef] [PubMed]

17. Partridge, S.R.; Kwong, S.M.; Firth, N.; Jensen, S.O. Mobile genetic elements associated with antimicrobial resistance. Clin. Microbiol. Rev. 2018, 31, 31. [CrossRef]

18. Partridge, S.R.; Tsafnat, G.; Coiera, E.; Iredell, J.R. Gene cassettes and cassette arrays in mobile resistance integrons. FEMS Microbiol. Rev. 2009, 33, 757-784. [CrossRef]

19. Minakhina, S.; Kholodii, G.; Mindlin, S.; Yurieva, O.; Nikiforov, V. Tn5053 family transposons are res site hunters sensing plasmidal res sites occupied by cognate resolvases. Mol. Microbiol. 1999, 33, 1059-1068. [CrossRef]

20. Rådström, P.; Sköld, O.; Swedberg, G.; Flensburg, J.; Roy, P.H.; Sundström, L. Transposon Tn5090 of plasmid R751, which carries an integron, is related to Tn7, Mu, and the retroelements. J. Bacteriol. 1994, 176, 3257-3268. [CrossRef]

21. Kholodii, G.; Mindlin, S.Z.; Bass, I.; Yurieva, O.; Minakhina, S.; Nikiforov, V. Four genes, two ends, and a res region are involved in transposition of Tn5053: A paradigm for a novel family of transposons carrying either a mer operon or an integron. Mol. Microbiol. 1995, 17, 1189-1200. [CrossRef]

22. Petrovski, S.; Blackmore, D.W.; Jackson, K.L.; Stanisich, V.A. Mercury(II)-resistance transposons Tn502 and Tn512, from Pseudomonas clinical strains, are structurally different members of the Tn5053 family. Plasmid 2011, 65, 58-64. [CrossRef]

23. Mindlin, S.; Kholodii, G.; Gorlenko, Z.; Minakhina, S.; Minakhin, L.; Kalyaeva, E.; Kopteva, A.; Petrova, M.; Yurieva, O.; Nikiforov, V. Mercury resistance transposons of Gram-negative environmental bacteria and their classification. Res. Microbiol. 2001, 152, 811-822. [CrossRef]

24. Haines, A.S.; Akhtar, P.; Stephens, E.R.; Jones, K.; Thomas, C.M.; Perkins, C.D.; Williams, J.R.; Day, M.J.; Fry, J.C. Plasmids from freshwater environments capable of IncQ retrotransfer are diverse and include pQKH54, a new IncP-1 subgroup archetype. Microbiology 2006, 152, 2689-2701. [CrossRef] [PubMed]

25. Yurieva, O.; Kholodii, G.; Minakhin, L.; Gorlenko, Z.; Kalyaeva, E.; Mindlin, S.; Nikiforov, V. Intercontinental spread of promiscuous mercury-resistance transposons in environmental bacteria. Mol. Microbiol. 1997, 24, 321-329. [CrossRef] [PubMed]

26. Mindlin, S.; Minakhin, L.; Petrova, M.; Kholodii, G.; Minakhina, S.; Gorlenko, Z.; Nikiforov, V. Present-day mercury resistance transposons are common in bacteria preserved in permafrost grounds since the Upper Pleistocene. Res. Microbiol. 2005, 156, 994-1004. [CrossRef]

27. Mindlin, S.; Petrova, M. Mercury resistance transposons. In Bacterial Integrative Mobile Genetic Elements; Roberts, A.P., Mullany, P., Eds.; Landes Biosciences: Austin, TX, USA, 2013; pp. 33-52.

28. Kos, V.N.; Déraspe, M.; McLaughlin, R.E.; Whiteaker, J.D.; Roy, P.H.; Alm, R.A.; Corbeil, J.; Gardner, H. The resistome of Pseudomonas aeruginosa in relationship to phenotypic susceptibility. Antimicrob. Agents Chemother. 2015, 59, 427-436. [CrossRef]

29. Brown, H.J.; Stokes, H.W.; Hall, R.M. The integrons In0, In2, and In5 are defective transposon derivatives. J. Bacteriol. 1996, 178, 4429-4437. [CrossRef]

30. Gillings, M.R. Integrons: Past, present, and future. Microbiol. Mol. Biol. Rev. 2014, 78, 257-277. [CrossRef]

31. Ghaly, T.M.; Chow, L.; Asher, A.J.; Waldron, L.S.; Gillings, M.R. Evolution of class 1 integrons: Mobilization and dispersal via food-borne bacteria. PLoS ONE 2017, 12, e0179169. [CrossRef] 
32. Van der Auwera, G.A.; Król, J.E.; Suzuki, H.; Foster, B.; Van Houdt, R.; Brown, C.J.; Mergeay, M.; Top, E.M. Plasmids captured in C. metallidurans CH34: Defining the PromA family of broad-host-range plasmids. Antonie Van Leeuwenhoek 2009, 96, 193-204. [CrossRef]

33. Zhang, M.; Brons, J.K.; van Elsas, J.D. The complete sequences and ecological roles of two IncP-1 $\beta$ plasmids, pHB44 and pBS64, isolated from the mycosphere of Laccaria proxima. Front. Microbiol. 2016, 7, 909. [CrossRef]

34. Mindlin, S.Z.; Minakhina, S.V.; Kholodiǔ, G.; Kopteva, A.V.; Nikiforov, V.G. Incorporation of Tn5053 and Tn402 into various plasmids. Genetika 1996, 32, 1426-1430.

35. Kamali-Moghaddam, M.; Sundstrom, L. Transposon targeting determined by resolvase. FEMS Microbiol. Lett. 2000, 186, 55-59. [CrossRef]

36. Kamali-Moghaddam, M. Arrayed transposase-binding sequences on the ends of transposon $\operatorname{Tn} 5090 / \operatorname{Tn} 402$. Nucl. Acids Res. 2001, 29, 1005-1011. [CrossRef]

37. Petrovski, S.; Stanisich, V.A. Tn502 and Tn512 Are res site hunters that provide evidence of resolvase-independent transposition to random sites. J. Bacteriol. 2010, 192, 1865-1874. [CrossRef] [PubMed]

38. Chowdhury, P.R.; Scott, M.; Worden, P.; Huntington, P.; Hudson, B.; Karagiannis, T.; Charles, I.G.; Djordjevic, S.P. Genomic islands 1 and 2 play key roles in the evolution of extensively drug-resistant ST235 isolates of Pseudomonas aeruginosa. Open Biol. 2016, 6. [CrossRef]

39. Sinclair, M.; Holloway, B.W. A chromosomally located transposon in Pseudomonas aeruginosa. J. Bacteriol. 1982, 151, 569-579. [CrossRef]

40. Partridge, S.R.; Brown, H.J.; Hall, R.M. Characterization and movement of the class 1 integron known as Tn2521 and Tn1405. Antimicrob. Agents Chemother. 2002, 46, 1288-1294. [CrossRef]

41. Petrova, M.; Gorlenko, Z.; Mindlin, S.Z. Tn5045, a novel integron-containing antibiotic and chromate resistance transposon isolated from a permafrost bacterium. Res. Microbiol. 2011, 162, 337-345. [CrossRef]

42. Hanahan, D. Studies on transformation of Escherichia coli with plasmids. J. Mol. Biol. 1983, 166, 557-580. [CrossRef]

43. Palombo, E.A.; Yusoff, K.; Stanisich, V.A.; Krishnapillai, V.; Willetts, N. Cloning and genetic analysis of tra cistrons of the Tra 2/Tra 3 region of plasmid RP1. Plasmid 1989, 22, 59-69. [CrossRef]

44. Stanisich, V.A.; Bennett, P.M.; Oritz, J.M. A molecular analysis of transductional marker rescue involving P-group plasmids in Pseudomonas aeruginosa. Mol. Gen. Genet. MGG 1976, 143, 333-337. [CrossRef] [PubMed]

45. Lyras, D.; Palombo, E.A.; Stanisich, V.A. Characterization of a Tra 2 function of RP1 that affects growth of Pseudomonas aeruginosa PAO and surface exclusion in Escherichia coli K12. Plasmid 1992, 27, 105-118. [CrossRef]

46. Sambrook, J.; Fritsch, E.F.; Maniatis, T. Molecular Cloning: A Laboratory Manual; Cold Spring Harbor Laboratory Press: Cold Spring Harbor, NY, USA, 1989.

47. Wick, R.R.; Judd, L.M.; Gorrie, C.L.; Holt, K.E. Unicycler: Resolving bacterial genome assemblies from short and long sequencing reads. PLoS Comput. Biol. 2017, 13, e1005595. [CrossRef] [PubMed]

48. Bennett, P.M.; Grinsted, J.; Richmond, M.H. Transposition of TnA does not generate deletions. Mol. Genet. Genom. 1977, 154, 205-211. [CrossRef]

49. Wallace, L.J.; Ward, J.M.; Richmond, M.H. The $\operatorname{tnpR}$ gene product of TnA is required for transposition immunity. Mol. Genet. Genom. 1981, 184, 87-91. [CrossRef]

50. Rose, R.E. The nucleotide sequence of pACYC184. Nucl. Acids Res. 1988, 16, 355. [CrossRef]

51. Bolivar, F. Construction and characterization of new cloning vehicles III. Derivatives of plasmid pBR322 carrying unique Eco RI sites for selection of Eco RI generated recombinant DNA molecules. Gene 1978, 4, 121-136. [CrossRef]

52. Yusoff, K.; Stanisich, V.A. Location of a function on RP1 that fertility inhibits IncW plasmids. Plasmid 1984, 11, 178-181. [CrossRef]

53. Stanisich, V.A.; Arwas, R.; Bennett, P.M.; De La Cruz, F. Characterization of Pseudomonas mercury-resistance transposon Tn502, which has a preferred insertion site in RP1. Microbiology 1989, 135, 2909-2915. [CrossRef]

54. Haines, A.S.; Jones, K.; Batt, S.M.; Kosheleva, I.A.; Thomas, C.M. Sequence of plasmid pBS228 and reconstruction of the IncP-1 $\alpha$ phylogeny. Plasmid 2007, 58, 76-83. [CrossRef] [PubMed] 
55. Kholodii, G.; Gorlenko, Z.; Mindlin, S.; Hobman, J.; Nikiforov, V. Tn5041-like transposons: Molecular diversity, evolutionary relationships and distribution of distinct variants in environmental bacteria. Microbiology 2002, 148, 3569-3582. [CrossRef] [PubMed]

56. Szuplewska, M.; Ludwiczak, M.; Lyzwa, K.; Czarnecki, J.; Bartosik, D. Mobility and generation of mosaic non-autonomous transposons by Tn3-derived Inverted-Repeat Miniature Elements (TIMEs). PLoS ONE 2014, 9, e105010. [CrossRef] [PubMed]

57. Schneiker, S.; Keller, M.; Dröge, M.; Lanka, E.; Pühler, A.; Selbitschka, W. The genetic organization and evolution of the broad host range mercury resistance plasmid pSB102 isolated from a microbial population residing in the rhizosphere of alfalfa. Nucl. Acids Res. 2001, 29, 5169-5181. [CrossRef]

58. Partridge, S.R. Analysis of antibiotic resistance regions in Gram-negative bacteria. FEMS Microbiol. Rev. 2011, 35, 820-855. [CrossRef]

59. Stokes, H.W.; Elbourne, L.D.H.; Hall, R.M. Tn1403, a multiple-antibiotic resistance transposon made up of three distinct transposons. Antimicrob. Agents Chemother. 2007, 51, 1827-1829. [CrossRef]

60. Tseng, S.-P.; Tsai, J.-C.; Teng, L.-J.; Hsueh, P.-R. Dissemination of transposon Tn6001 in carbapenem-non-susceptible and extensively drug-resistant Pseudomonas aeruginosa in Taiwan. J. Antimicrob. Chemother. 2009, 64, 1170-1174. [CrossRef]

61. Chowdhury, P.R.; Merlino, J.; Labbate, M.; Cheong, E.Y.-L.; Gottlieb, T.; Stokes, H.W. Tn6060, a transposon from a genomic island in a Pseudomonas aeruginosa clinical isolate that includes two class 1 integrons. Antimicrob. Agents Chemother. 2009, 53, 5294-5296. [CrossRef]

62. Coyne, S.; Courvalin, P.; Galimand, M. Acquisition of multidrug resistance transposon Tn6061 and IS6100-mediated large chromosomal inversions in Pseudomonas aeruginosa clinical isolates. Microbiology 2010, 156, 1448-1458. [CrossRef]

63. Greated, A.; Lambertsen, L.; Williams, P.A.; Thomas, C.M. Complete sequence of the IncP-9 TOL plasmid pWW0 from Pseudomonas putida. Environ. Microbiol. 2002, 4, 856-871. [CrossRef]

64. Botelho, J.; Roberts, A.P.; León-Sampedro, R.; Grosso, F.; Peixe, L. Carbapenemases on the move: It's good to be on ICEs. Mob. DNA 2018, 9, 37. [CrossRef]

65. Kropinski, A.M.; Farinha, M.A.; Jansons, I. Nucleotide sequence of the Pseudomonas aeruginosa insertion Sequence IS222: Another Member of the IS3 Family. Plasmid 1994, 31, 222-228. [CrossRef]

66. Kiewitz, C.; Larbig, K.; Klockgether, J.; Weinel, C.; Tümmler, B. Monitoring genome evolution ex vivo: Reversible chromosomal integration of a $106 \mathrm{~kb}$ plasmid at two tRNA(Lys) gene loci in sequential Pseudomonas aeruginosa airway isolates. Microbiology 2000, 146, 2365-2373. [CrossRef]

67. Qiu, X.; Gurkar, A.U.; Lory, S. Interstrain transfer of the large pathogenicity island (PAPI-1) of Pseudomonas aeruginosa. Proc. Natl. Acad. Sci. USA 2006, 103, 19830-19835. [CrossRef]

68. Botelho, J.; Mourão, J.; Roberts, A.P.; Peixe, L. Comprehensive genome data analysis establishes a triple whammy of carbapenemases, ICEs and multiple clinically relevant bacteria. Microb. Genom. 2020, 6. [CrossRef]

69. Guglielmini, J.; Quintais, L.; Garcillán-Barcia, M.P.; de la Cruz, F.; Rocha, E.P. The repertoire of ICE in prokaryotes underscores the unity, diversity, and ubiquity of conjugation. PLoS Genet. 2011, 7, e1002222. [CrossRef]

70. Carter, M.Q.; Chen, J.; Lory, S. The Pseudomonas aeruginosa pathogenicity island PAPI-1 is transferred via a novel type IV pilus. J. Bacteriol. 2010, 192, 3249-3258. [CrossRef]

71. Bellanger, X.; Payot, S.; Leblond-Bourget, N.; Guédon, G. Conjugative and mobilizable genomic islands in bacteria: Evolution and diversity. FEMS Microbiol. Rev. 2014, 38, 720-760. [CrossRef]

72. Toleman, M.A.; Walsh, T.R. Combinatorial events of insertion sequences and ICE in Gram-negative bacteria. FEMS Microbiol. Rev. 2011, 35, 912-935. [CrossRef]

73. Molina, L.; Duque, E.; Gómez, M.J.; Krell, T.; Lacal, J.; García-Puente, A.; García, V.; Matilla, M.A.; Ramos, J.L.; Segura, A. The pGRT1 plasmid of Pseudomonas putida DOT-T1E encodes functions relevant for survival under harsh conditions in the environment. Environ. Microbiol. 2011, 13, 2315-2327. [CrossRef]

74. Nakazawa, T. Travels of a Pseudomonas, from Japan around the world. Environ. Microbiol. 2002, 4, 782-786. [CrossRef]

75. Wu, X.; Monchy, S.; Taghavi, S.; Zhu, W.; Ramos, J.; van der Lelie, D. Comparative genomics and functional analysis of niche-specific adaptation in Pseudomonas putida. FEMS Microbiol. Rev. 2011, 35, 299-323. [CrossRef] 
76. Baggi, G.; Barbieri, P.; Galli, E.; Tollari, S. Isolation of a Pseudomonas stutzeri strain that degrades o-xylene. Appl. Environ. Microbiol. 1987, 53, 2129-2132. [CrossRef]

77. Coetzee, J.N. Mobilization of the Proteus mirabilis Chromosome by R plasmid R772. J. Gen. Microbiol. 1978, 108, 103-109. [CrossRef]

78. Williams, P.A.; Jones, R.M.; Shaw, L.E. A Third transposable element, ISPpu12, from the toluene-xylene catabolic plasmid pWW0 of Pseudomonas putida mt-2. J. Bacteriol. 2002, 184, 6572-6580. [CrossRef]

79. Kamachi, K.; Sota, M.; Tamai, Y.; Nagata, N.; Konda, T.; Inoue, T.; Top, E.M.; Arakawa, Y. Plasmid pBP136 from Bordetella pertussis represents an ancestral form of IncP-1 $\beta$ plasmids without accessory mobile elements. Microbiology 2006, 152, 3477-3484. [CrossRef] [PubMed]

80. Smalla, K.; Haines, A.S.; Jones, K.; Krögerrecklenfort, E.; Heuer, H.; Schloter, M.; Thomas, C.M. Increased Abundance of IncP-1 $\beta$ plasmids and mercury resistance genes in mercury-polluted river sediments: First discovery of IncP-1 $\beta$ plasmids with a complex mer transposon as the sole accessory element. Appl. Environ. Microbiol. 2006, 72, 7253-7259. [CrossRef]

81. Dealtry, S.; Ding, G.-C.; Weichelt, V.; Dunon, V.; Schlüter, A.; Martini, M.C.; Del Papa, M.F.; Lagares, A.; Amos, G.C.A.; Wellington, E.M.H.; et al. Cultivation-independent screening revealed hot spots of IncP-1, IncP-7 and IncP-9 plasmid occurrence in different environmental habitats. PLoS ONE 2014, 9, e89922. [CrossRef]

82. Klockgether, J.; Cramer, N.; Wiehlmann, L.; Davenport, C.F.; Tümmler, B. Pseudomonas aeruginosa genomic structure and diversity. Front. Microbiol. 2011, 2, 150. [CrossRef]

83. Sevastsyanovich, Y.R.; Krasowiak, R.; Bingle, L.E.H.; Haines, A.S.; Sokolov, S.; Kosheleva, I.A.; Leuchuk, A.A.; Titok, M.; Smalla, K.; Thomas, C.M. Diversity of IncP-9 plasmids of Pseudomonas. Microbiology 2008, 154, 2929-2941. [CrossRef]

84. Benson, S.; Shapiro, J. TOL is a broad-host-range plasmid. J. Bacteriol. 1978, 135, 278-280. [CrossRef] [PubMed]

85. Klockgether, J.; Würdemann, D.; Reva, O.; Wiehlmann, L.; Tümmler, B. Diversity of the abundant pKLC102/PAGI-2 family of genomic islands in Pseudomonas aeruginosa. J. Bacteriol. 2007, 189, 2443-2459. [CrossRef] [PubMed]

86. Chowdhury, P.R.; Scott, M.J.; Djordjevic, S.P. Genomic islands 1 and 2 carry multiple antibiotic resistance genes in Pseudomonas aeruginosa ST235, ST253, ST111 and ST175 and are globally dispersed. J. Antimicrob. Chemother. 2016, 72, 620-622. [CrossRef] [PubMed]

87. Klockgether, J.; Reva, O.; Larbig, K.; Tümmler, B. Sequence analysis of the mobile genome island pKLC102 of Pseudomonas aeruginosa C. J. Bacteriol. 2004, 186, 518-534. [CrossRef]

88. Szczepanowski, R.; Eikmeyer, F.; Harfmann, J.; Blom, J.; Rogers, L.M.; Top, E.M.; Schlüter, A. Sequencing and comparative analysis of IncP- $1 \alpha$ antibiotic resistance plasmids reveal a highly conserved backbone and differences within accessory regions. J. Biotechnol. 2011, 155, 95-103. [CrossRef]

Publisher's Note: MDPI stays neutral with regard to jurisdictional claims in published maps and institutional affiliations.

(C) 2020 by the authors. Licensee MDPI, Basel, Switzerland. This article is an open access article distributed under the terms and conditions of the Creative Commons Attribution (CC BY) license (http://creativecommons.org/licenses/by/4.0/). 